\title{
The Drosophila neurogenic locus mastermind encodes a nuclear protein unusually rich in amino acid homopolymers
}

\author{
David Smoller, ${ }^{1}$ Christina Friedel, Aloisia Schmid, Donald Bettler, Lee Lam, and Barry Yedvobnick ${ }^{2}$ \\ Department of Biology, Emory University, Atlanta, Georgia 30322 USA
}

\begin{abstract}
The neurogenic loci of Drosophila are required for proper partitioning of ectodermal cells into epidermal versus neural lineages. The loci appear to encode components of a developmental pathway involving cellular communication. In an effort to understand the role of the neurogenic locus mastermind in these processes, we have characterized its expression and sequence. The locus produces a number of transcripts that accumulate ubiquitously during early embryogenesis but more specifically in the central nervous system during later stages. Sequence analysis of a major cDNA product predicts an unusual protein containing an abundance of amino acid homopolymers and charge clusters typical of regulatory molecules. Nearly half of the mass of the predicted protein derives from only three amino acids: glutamine, glycine, and asparagine. Immunohistochemical studies of the protein in cell culture and early embryos show that the protein accumulates predominately in the nucleus.
\end{abstract}

[Key Words: Drosophila; neurogenesis; mastermind; homopolymers; nuclear]

Received June 27, 1990; revised version accepted August 8, 1990.

The establishment of neural and epidermal lineages within the Drosophila ectoderm requires the action of a small group of genes, termed the neurogenic loci (Lehmann et al. 1983; Hartenstein and Campos-Ortega 1984, 1986). Six zygotic neurogenic loci have been identified: Notch $(N)$, Delta $(D I)$, Enhancer of split $[E(s p l)]$, big brain (bib), mastermind (mam), and neuralized (neu), as well as a number of maternal effect neurogenic loci, including almondex $(a m x)$ and pecanex $(p c x)$ (Perrimon et al. 1986; LaBonne et al. 1989). Loss of neurogenic gene function leads to a uniform commitment of cells within the neurogenic region to the neural pathway and the concomitant loss of epidermis, suggesting the hypothesis that these loci encode components of a pathway that represses neural development /Wright 1970). Consistent with this idea, inhibitory interactions among cells of insect neuroectoderm have been demonstrated through laser ablation (Doe and Goodman $1985 \mathrm{a}, \mathrm{b}$ ), and numerous genetic interactions among mutations in the neurogenic loci have been reported (Vassin et al. 1985; de la Concha et al. 1988; Shepard et al. 1989; Brand and Campos-Ortega 1990; Xu et al. 1990). Since the formulation of this hypothesis, the notion that these loci encode molecules involved in the signaling, reception, and transduction of developmental cues has also

'Present address: Department of Genetics, Washington University School of Medicine, St. Louis, Missouri 63110 USA.

${ }^{2}$ Corresponding author. received considerable experimental support from molecular studies. The $N$ and $D I$ loci code for transmembrane proteins with putative ligand-binding domains related to mammalian epidermal growth factor (Wharton et al. 1985a; Kidd et al. 1986, 1989; Vassin et al. 1987; Kopczynski et al. 1988; Johansen et al. 1989). Transfected Drosophila cells that express $N$ and $D l$ proteins form mixed aggregrates, apparently mediated through the physical interaction of these molecules (Fehon et al. 1990). Recent results from mosaic analyses are also consistent with a role for $N$ as a receptor or adhesion molecule during these processes (Hoppe and Greenspan 1990). The predicted product of the bib locus is similar to transmembrane channel proteins (Rao et al. 1990), and partial sequence of the $p c x$ locus is also suggestive of a membrane-spanning product (LaBonne et al. 1989). Finally, DNA sequence analyses have shown that the $E$ (spl) region encodes a protein homologous to a mammalian G protein (Hartley et al. 1988), as well as proteins homologous to the vertebrate myc family of nuclear proteins (Klambt et al. 1989).

The object of this study, mam, exhibits genetic interactions with several neurogenic loci during central nervous system (CNS) formation (de la Concha et al. 1988). Furthermore, postembryonic interactions have been characterized between alleles of the $N$ locus and mam (Brand and Campos-Ortega 1990; Xu et al. 1990). Thus, it appears that the functions of the $N$ and mam loci may be intimately associated during neurogenesis 
and during other developmental processes as well. In an effort to understand the basis for these interactions and the role of mam during neurogenesis, a molecular characterization of the product of this locus has been undertaken. Previous molecular studies demonstrated that the mam locus is large and unusually rich in repetitive elements, most notably opa or $(\mathrm{CAX})_{\mathbf{n}}$ runs (Weigel et al. 1987; Yedvobnick et al. 1988). Here, we report that the unusual genomic organization of mam is reflected in its predicted protein product as numerous runs of amino acid homopolymers. Further, mam is transcriptionally complex, producing a number of RNAs during and after neuroblast segregation. During early neurogenesis, mam products are observed throughout the germ band. In contrast, late mam products accumulate in the CNS, implicating the locus in functions beyond the neural-epidermal lineage determination. Immunohistochemical localizations of mam protein in cell culture and embryos demonstrate that the product accumulates predominantly in the nucleus.

\section{Results}

Definition of the mam transcription unit

The molecular cloning of the region containing mam was reported previously (Weigel et al. 1987; Yedvobnick et al. 1988). A physical map covering $90 \mathrm{~kb}$ of the mam region is presented in Figure 1A. The locus is likely to be contained within a $76 \cdot \mathrm{kb}$ chromosomal interval $\mid-51$ to +25 on the physical map/ and, based on transcriptional analyses (summarized below), the locus appears to extend $67 \mathrm{~kb}$.

Initial characterizations of the locus demonstrated a high density of repeated sequences. DNA sequence of several regions revealed two classes of repeat: opa $(\mathrm{CAX})_{\mathbf{n}}$ and $(\mathrm{CA})_{\mathbf{n}}$ (Yedvobnick et al. 1988). The repeats complicated the analysis of mam transcription, because they are highly transcribed at many genomic sites. Unique sequence regions that were tested for transcription gave negative results, suggesting that particular repeats must be components of exons. This seemed most

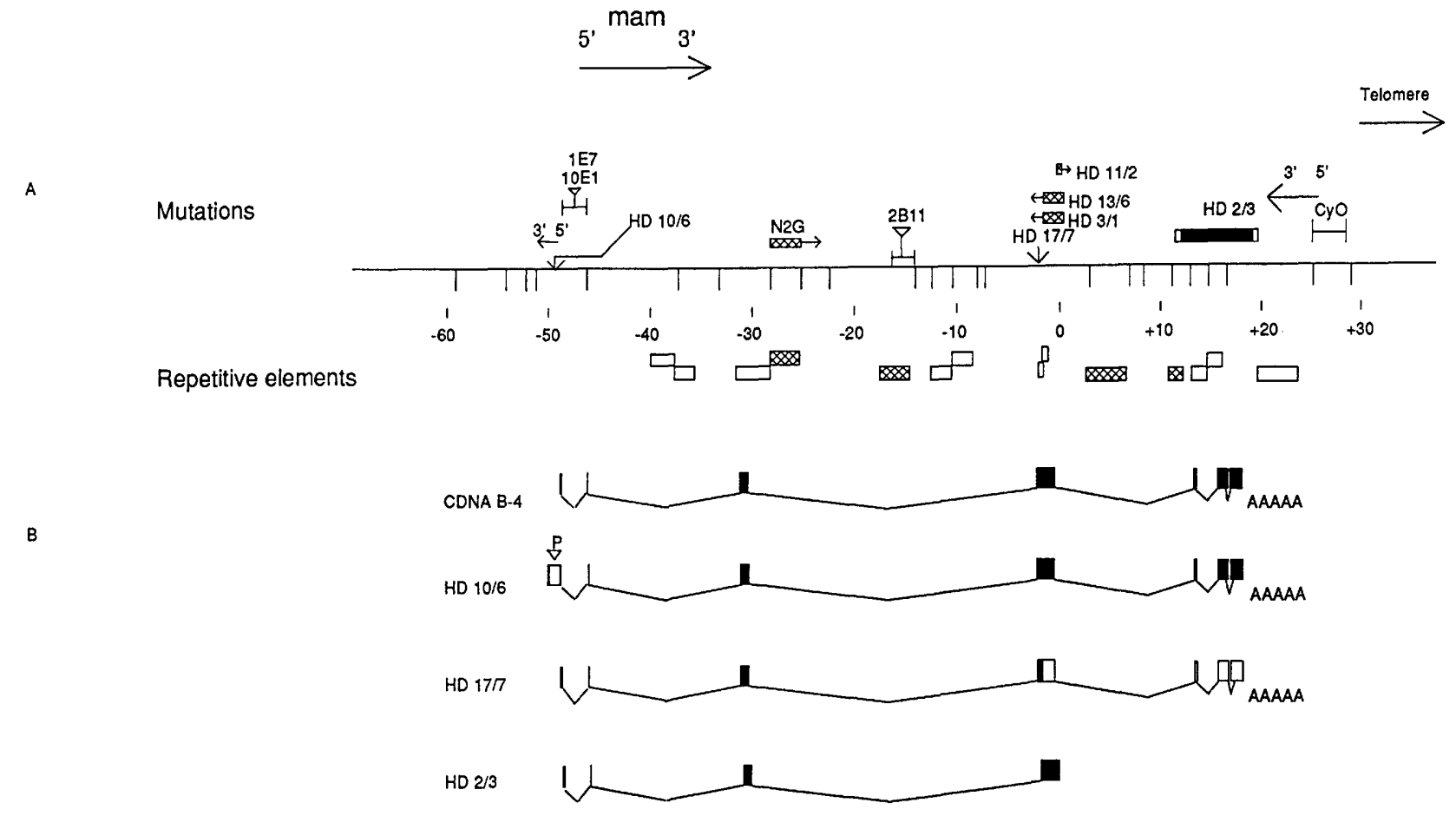

Figure 1. Molecular organization of mam. (A) The horizontal line depicts $90 \mathrm{~kb}$ of DNA from the mam region at cytogenetic position $50 \mathrm{CD}$. The EcoRI sites are indicated as vertical lines below the coordinate line. The coordinate scale below the line is indicated in kilobases, and the 0 coordinate marks the P-element insertion site cloned previously from the hybrid-dysgenesis (HD)-associated allele HD 11/2 (Yedvobnick et al. 1988). Repetitive regions containing opa (CAX $)_{\mathbf{n}}$ elements (open boxes) and (CA) $)_{\mathbf{n}}$ elements $(\mathrm{cross}-$ hatched boxes) are displayed below the coordinate line. The physical map positions of 10 mam alleles are shown above the coordinate line. Seven alleles were described previously: $\operatorname{In}(2 \mathrm{R}) N^{2 \mathrm{G}}, \mathrm{HD} 2 / 3, \mathrm{HD} 11 / 2, \mathrm{HD} 13 / 6, \mathrm{HD} 3 / 1, \mathrm{HD} 17 / 7$, and HD 10/6 (Yedvobnick et al. 1988). Arrows associated with breakpoint markers indicate the direction of particular inversions. HD 2/3, HD 17/7, and HD 10/6 are described below and in the text. Three additional mam alleles, 1E7, 10E1, and 2B11, were provided by the Jan lab and derived from an enhancer detection screen (Bier et al. 1989). A chromosome breakpoint associated with the CyO balancer limits the $3^{\prime}$ end of the locus. This breakpoint is spanned by a transcription unit oriented opposite to mam transcription that is expressed during early embryogenesis. The proximal $\left(5^{\prime}\right)$ region of mam is flanked by a maternally expressed gene that is also transcribed opposite to mam. $(B)$ Map of the mam cDNA B4 and proposed structure of the transcript in three characterized mutants. cDNA B4 is 6333 bp and contains seven exons $(312,127,1010,2073,286,1090$, and $1435 \mathrm{bp})$, spanning $67 \mathrm{~kb}$ of genomic DNA. Sequence analyses of HD $10 / 6$ and HD 17/7 are described in the text. The diagram depicts a P insertion within exon 1 of HD 10/6, a deletion and frameshift within exon 4 of $\mathrm{HD} 17 / 7$ (open boxes mark regions after deletion that are within frameshift), and an 8-kb deletion that removes exons 5,6 , and 7 in $\mathrm{HD} 2 / 3$. 
likely for opa elements, because they are often found within protein-coding regions (Laughon et al. 1985; Wharton et al. 1985b; Pirrotta et al. 1987). Consequently, we sequenced three opa-containing regions and searched for open reading frames (ORFs). The map positions of the sequenced regions were $-1,-2$, and -32 (Fig. 1A). In each case, opa comprised a portion of an ORF in which CAX coded for glutamine. The three ORFs had the same orientation, suggesting that they were parts of the same transcription unit. To test this idea, a synthetic oligonucleotide homologous to a nonrepetitive section of each ORF was hybridized to blots of gel-fractionated poly $(\mathrm{A})^{+}$RNA isolated from 3 to 12-hr embryos, a time period that spans neurogenesis. The probes hybridized to a group of transcripts (see below) and were subsequently utilized to screen cDNA libraries. The largest cDNA isolated, $\mathrm{B} 4(6.3 \mathrm{~kb})$, was recovered from 8- to 12-hr embryos. The cDNA was mapped against mam genomic clones under conditions that eliminate cross-hybridization of repetitive elements. B4 hybridized across $67 \mathrm{~kb}$ of DNA (Fig. 1B), and the limits of hybridization coincided well with the estimate of the physical limits of the locus. DNA sequence analysis of B4 and genomic exons indicate that B4 is nearly full length and contains all of the protein-coding information. DNA sequence determinations and physical mapping of three mam alleles, HD 10/6, HD 17/7, and $\mathrm{HD} 2 / 3$, have demonstrated small lesions within exons of B4, strongly implicating the B4 transcript in mam function (see below).

\section{Sequence analysis of mam P-element mutations and a revertant}

To establish a role for $\mathrm{B} 4$ in mam function, the sequence associated with two P-induced mam alleles and a revertant were determined. The mam allele $\mathrm{HD} 10 / 6$ is an insertion of a $P$ element near coordinate -50 on the physical map (Fig 1A; Yedvobnick et al. 1988). The insertion region from HD 10/6 was cloned and sequenced; this analysis revealed a $\mathrm{P}$ element within the first exon of B4 at nucleotide 23 (Figs. 1B and 3). The P element was mobilized through outcrossing to an $M$ strain and complementation testing against a mam allele. Approximately 17,000 chromosomes were tested, and two revertants were isolated. Genomic Southern analysis indicated that the P element had excised in both revertants. DNA sequence analysis of one revertant demonstrated a precise excision (data not shown); the second revertant was not analyzed further.

The mutation HD 17/7 was determined to be a small deletion near coordinate -2.0 (Yedvobnick et al. 1988). DNA sequence analysis of the deletion region has demonstrated that this allele is missing $146 \mathrm{bp}$ from exon 4 of B4 (nucleotides 1886-2031; Figs. 1B and 3). The predicted effect of this deletion is to produce a frameshifted and truncated version of the normal $\mathrm{B} 4$ protein. In the HD 17/7 product the initial 377 amino acids are normal, followed by 69 amino acids of frameshift, before a premature termination after residue 446 . Consistent with this major perturbation in protein structure, HD 17/7 shows the most severe neurogenic phenotype among the characterized P-induced alleles.

The structure of the B4 product in mutation HD $2 / 3$ is also presented in Figure 1B. The deletion region from this mutant was cloned and mapped to the 3 ' end of the transcription unit. The deletion extends from an intronic region, between exons 4 and 5 , to a site $\sim 2.5 \mathrm{~kb}$ distal to the end of $\mathrm{B} 4$. The predicted product from deletion HD $2 / 3$ would code for a truncated 923 -amino-acid protein.

\section{Transcription of mam}

Temporal and spatial patterns of mam transcripts were determined through hybridization of nonrepetitive sequence segments of cDNA B4 to RNA blots and embryonic tissue sections (Fig. 2). The probes hybridize to a maternal class of $6-\mathrm{kb}$ transcript $(0-2 \mathrm{hr})$ and to four zygotic transcripts (Fig. 2A, $\mathrm{A}^{\prime}$ ). Two transcripts of 8.5 and $8.0 \mathrm{~kb}$ accumulate to high levels during $2-16 \mathrm{hr}$ of embryogenesis. Two additional transcripts of 7.5 and $6.5 \mathrm{~kb}$ are not highly expressed during early stages $(0-8 \mathrm{hr})$; however, both transcripts accumulate over the following $8 \mathrm{hr}$. The quantity of all four transcripts decreases significantly during later stages, although longer autoradiographic exposures reveal persistent expression late in embryogenesis (data not shown). Higher levels of accumulation are evident again at late larval/early pupal stages.

To determine the spatial distribution of these transcripts during neurogenesis, ${ }^{35}$ S-labeled antisense RNA probes were hybridized to tissue sections of embryos. Hybridization was not detected with control sense probes of comparable specific activity. High levels of ubiquitous expression were observed during germ-band elongation $(\sim 5 \mathrm{hr}$ postfertilization), coincident with neuroblast segregation from the ectoderm (Fig. 2B, $B^{\prime}$ ). For example, RNA accumulates in the developing anterior and posterior midgut, as well as throughout the mesodermal and ectodermal layers of the germ band. The resolution of the hybridization signal did not allow us to distinguish whether neuroblasts were expressing mam RNA. However, as embryogenesis proceeds, mam transcription is more restricted to neural tissue. During later embryogenesis $(\sim 16 \mathrm{hr}$ postfertilization), RNA accumulates almost entirely within the ventral nerve cord and brain of the CNS (Fig. 2C, $\mathrm{C}^{\prime}$ ); the signal evident outside the CNS during this stage is significantly higher than that seen with sense control probes. A late function of mam in the CNS is unknown; however, it is interesting that the $N$ protein accumulates there concurrently (Johansen et al. 1989; Kidd et al. 1989). A comparison of the RNA blot to the tissue sections suggests that the smaller transcripts (6.5 and $7.5 \mathrm{~kb})$ accumulate specifically in neural tissue.

\section{Analysis of cDNA B4 and genomic DNA}

The sequence of cDNA B4 and genomic exons was de- 
A

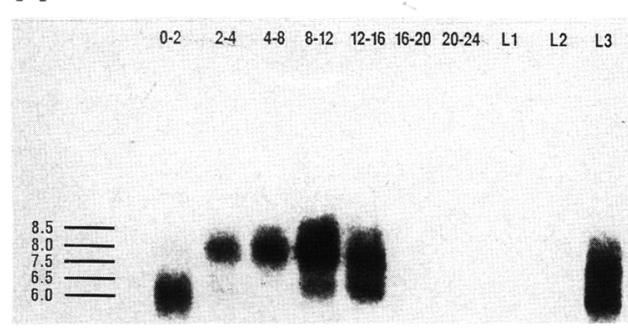

B

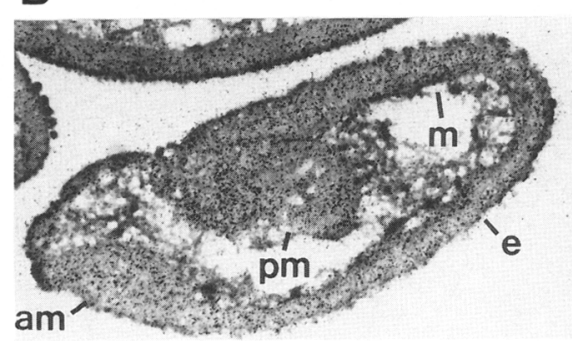

C

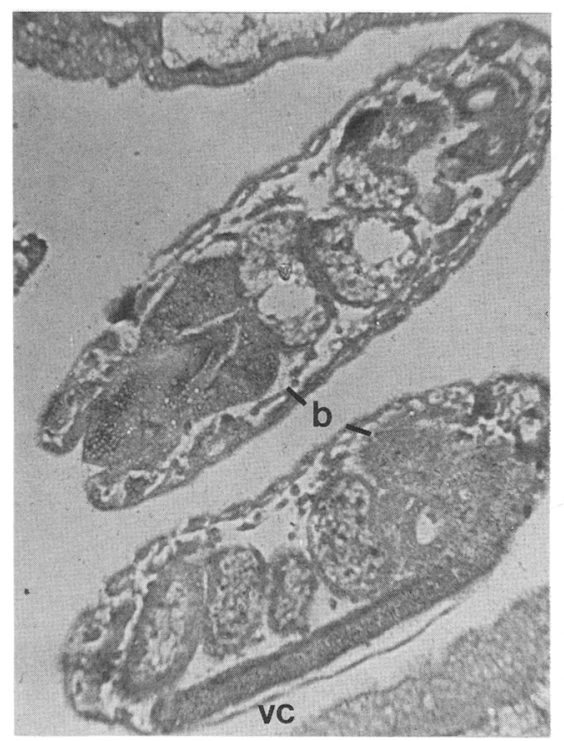

$A^{\prime}$

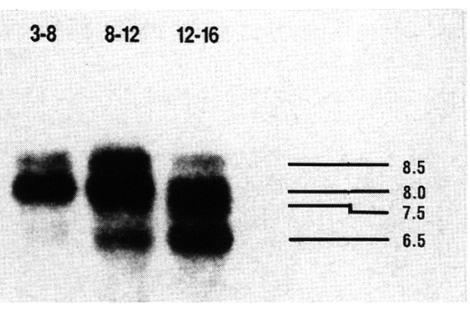

$\mathrm{B}^{\prime}$

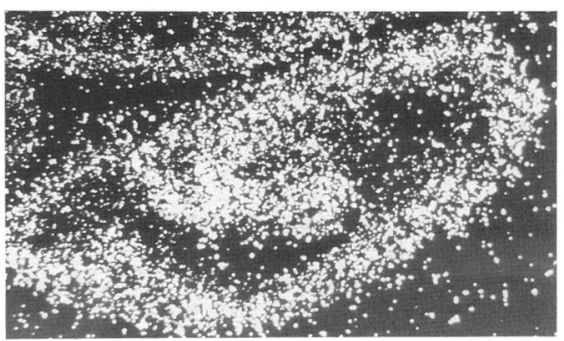

$c^{\prime}$

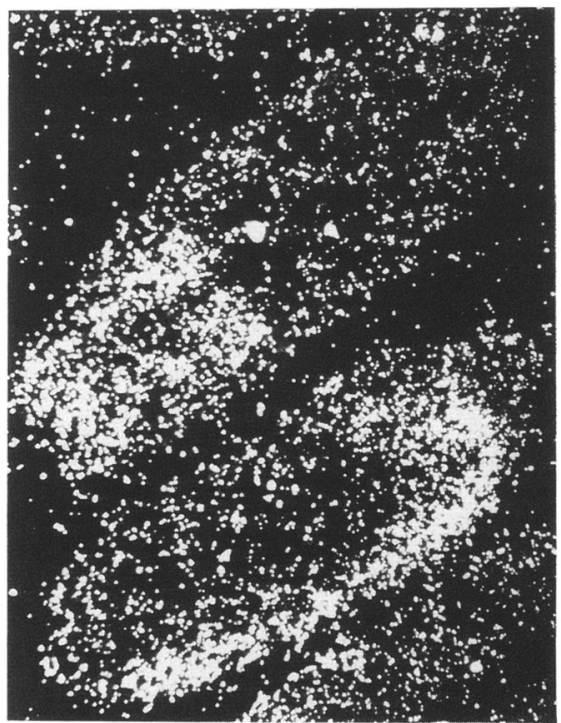

Figure 2. mam transcription patterns. $\left(A, A^{\prime}\right)$ Temporal accumulation of mam RNAs during embryogenesis. $(A \mid$ Ten micrograms of poly(A) ${ }^{+}$RNA from staged embryos (hours are postfertilization at $25^{\circ} \mathrm{C}$ ), or larval stages (L1, first instar; L2, second instar; L3, climbing third instar and early pupae) was electrophoresed, blotted onto nylon membranes, and hybridized with a ${ }^{32} \mathrm{P}-\mathrm{labeled} 900-\mathrm{bp}$ antisense RNA probe derived from cDNA B4. $\left\{A^{\prime}\right)$ Higher resolution RNA blot of embryonic transcripts. $\left(B, B^{\prime}\right)$ Spatial accumulation of mam RNAs during germ-band elongation (early neurogenesis); neuroblasts segregate from the ectoderm and layer between the ectoderm and mesoderm at this time $\left(\sim 5 \mathrm{hr}\right.$ postfertilization at $\left.25^{\circ} \mathrm{C}\right) .(B)$ Bright field; $\left(B^{\prime}\right)$ dark field. (am) Anterior midgut; (pm) posterior midgut; (e) ectoderm; $(\mathrm{m})$ mesoderm. $\left(C, C^{\prime}\right)$ Spatial accumulation of mam RNAs during late embryogenesis $(\sim 16 \mathrm{hr}$ postfertilization at $\left.25^{\circ} \mathrm{C}\right)$. Top and bottom are horizontal and sagittal sections, respectively, of similar age embryos. $(C)$ Bright field; $\left(C^{\prime}\right)$ dark field. (b) Brain; (vc) ventral nerve cord. Sections of embryos were hybridized with a $900-b p^{35}$ S-labeled antisense probe derived from the 3 ' end of cDNA B4.

termined (Fig. 3). This comparison revealed 16-base substitutions and four changes in the number of glutamines within a homopolymer run. The comparison of cDNA and genomic DNA established intron/exon boundaries; this is presented in Figures 1 and 3 . All boundaries matched the consensus for eukaryotes (Mount 1982). The cDNA encodes an ORF of $4788 \mathrm{bp}$, predicting a polypeptide of $167 \mathrm{kD}$ (1596 amino acids; see immunoblot, Fig. 5A, below). The ORF is preceded by $753 \mathrm{bp}$ of untranslated sequence and followed by a 791-bp 3'-untranslated region. A poly(A) tail is preceded by several imperfect matches to the consensus polyadenylation signal AATAAA (Proudfoot and Brownlee 1976); that is, TATAAA at position 6290 . The ATG at position 754 is 
ttttcgetgcgatttgttgtatttgtc aacacagacacatacgcacacacgtaacacacacacacacagacgctccgacgaaagagagtgttctggetttcactggccactgtgt ccgcgttcctatggttg tatctcggctgcatgttt ccgat acatt tggggggcgact gagtgtgtgtgagggccagagtt ggcagactgatgt aat tgt cgaataacgtaacgtaacaagag taccagggatgcgagccaat at t taagcgatactttagcgtaatgttatacgagtttaaattttagttgaaatgtacaaatatgtaaaatgtttatctatttaaa gctgcaaatgaatgctcattataaatatttaacaatgatatttatttact tattatt taaacctattcagttacttaattgcgacaagtggcact taataaat aaacatt gtggaaacattttcacttcaaaatt tatttcttgataacaaaatcggctttttaattcaaatataatttttgtgactaaataagcagtgctgcca tacat tcaactggaaacat cgtcagcaacagaaggataagtaatcgct tgat cgat agcgttat cgatgt tt tcccagccatcgttccaccact agcgcctctc AAAACAACAAAAAAACAGGGCAGTCGGACGCGGTTTTTATCATCGAGCGCGGTTTCTTTGTTTTAGCGCTCGAAAATTGTCGAGAACTCTCGTAAAAAATACAC TGTACCAAATAACTAAGGAGTGCATGCTAATTGAACAAGCAAATGAATTAAGGTGTATATCAAAGTGAAAAGAAGTCAAACATAACCGATTTTGTTGGCGGCTTT CTTTTATTTTTGTTGAGATACCGTGTTTAATTTCTCCAGTTTTATGCAAACACATGAATAACATAACAGTGGAAATTTCTAACAGTGCATTGTGAGATAAAATTG GATTAAAATTCAAAGCATTGGATAAATGCT TAGTTGAAATAACAACAGAAATAACAAATGGAAAATAGCAAATAGCAAATCAAAGGAAATCAAAATCAAGTTGGA TTATCAGCACAGCTTCTGGGACTTGCCACAGAATGTGCACTTGGTTTTCTTGTGGATGCTTTCACCTACCGCAGCAGCGATATTCCTAACACCTCTCCGCGTAGA ATAGGCATTTCCGGTGTGCAGTGCGGAAACAGCAGCAGCAGCAGCAGCGCTGCTAGCAACATCGGGCGATATCAGATATAGACAACCTATATACACATATATAT TTATTCGCCGCCGCTGTCGCGCCTTGTTCTTCGCGATTTCGTCGCCGTCAGCGTTCGCCGCCGACTGAGACGAAAGCTGCGAAGCAACGAGCGCTAGCGAAAGC CTCACCACGGACGCATTTATGGATGCGGGCGGCCTACCAGTTTTCCAGAGCGCCAGCCAAGCAGCCGCCGTCGCCCAGCAGCAGCAACAGCAGCAGCAGCAACAA CATTTGAATCTCCAGTTGCATCAGCAACACTTGGGCCTCCATCTGCAGCAGCAACAGCAGCTGCAACTGCAACAGCAGCAGCACAATGCCCAGGCGCAGCAGCAG CAGATCCAAGTTCAGCAGCAGCAGCAGCAGCAGCAGCAACAACAGCAGCAGCAGCAGCAACACTCGCCCTACAATGCAAACCTGGGAGCAACAGGCGGCATTGCT GGAATCACTGGCGGCAACGGAGCTGGCGGCCCTACAAATCCAGGAGCGGTACCCACCGCTCCGGGCGACACTATGCCCACCAAGCGGATGCCGGTCGTCGATCGG

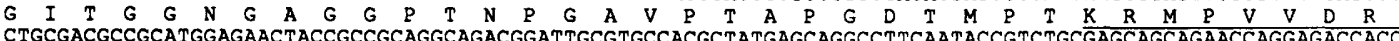

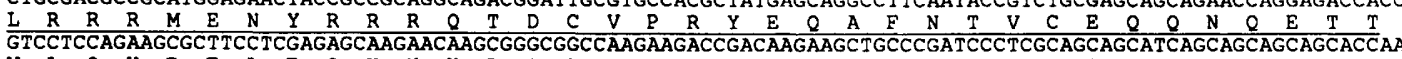

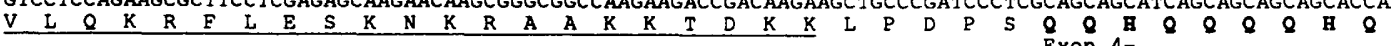
CAGCAGCAGCAGCATCAGCAGCACCAGCAACACCAGCAGGCCCAAACTATGTTAGCCGGACAGCTGCAGAGCAGTGTTCATGTGCAACAAAAATTCCTGAAACGA

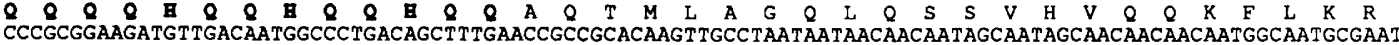
CCCGCGGAAGATGTTGACAATGGCCCTGACAGCTTTGAACCGCCGCACAAGTTGCCTAATAATAACAACAATAGCAATAGCAACAACAACAATGGCAATGCGAAT GCCAACAACGGCGGCAATGGCTCCAATACCGGCAACAACACAAACAACAATGGCAACAGCACCAACAACAACGGCGGCAGCAACAACAACGGCTCTGAGAATCTA

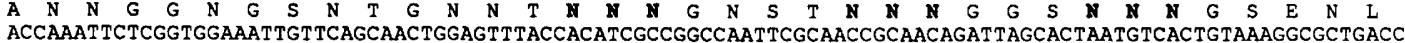

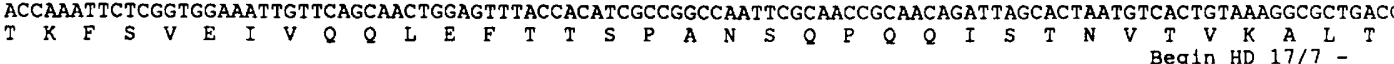

AACACATCGGTGAAAAGTGAACCAGGTGTGGGCGGTGGCGGAGGGGGCGGCGGTGGAGGCAATAGCGGTAACAACAATAACAACGGAGGCGGGGGAGGCGGCGGA

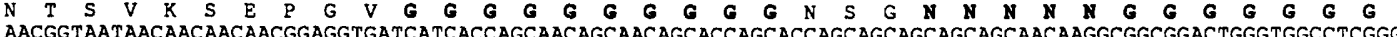

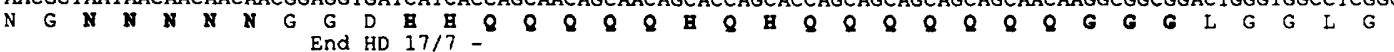

AATAATGGAAGGGGCGGGGGACCCGGCGGCATGGCGACGGGTCCCGGGGGCGTGGCCGGTGGACTTGGCGGCATGGGCATGCCACCCAACATGATGTCCGCCCAA

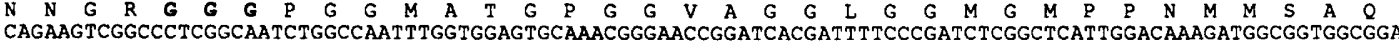

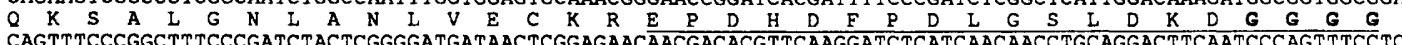

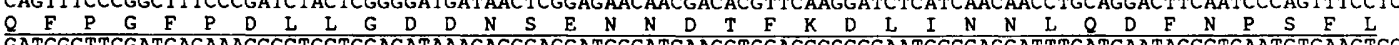

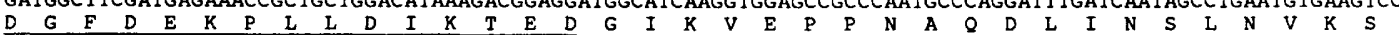
GAGGGCGGTTTGGGTCATGGTTTCGGTGGCTTTGGCCTGGGTCTGGACAATCCGGGCATGAAGATGCGTGGCGGCAATCCTGGCAACCAAGGTGGCTTTCCCAAC

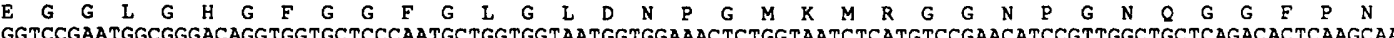

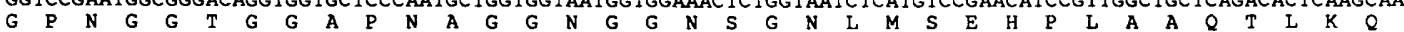
ATGGCCGAGCAGCATCAGCACAAGAATGCCATGGGCGGCATGGgTGGATTCCCACGACCGCCGCACGgCATGAATCCGCAGCAACAGCAGCAGCAGCAACAACAG M A E

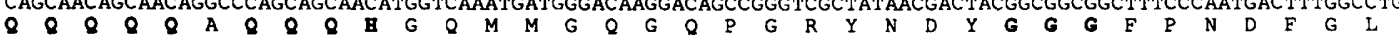

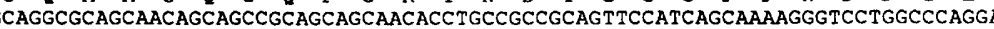

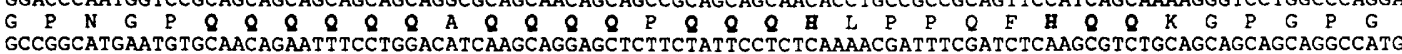

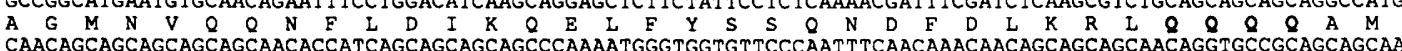
CAACAGCAGCAGCAGCAGCAACACCATCAGCAGCAGCAGCCCAAAATGGGTGGTTTCCCAATT TCAACAAACAACAGCAGCAGCAACAGGTGCCGCAGCAGCAA

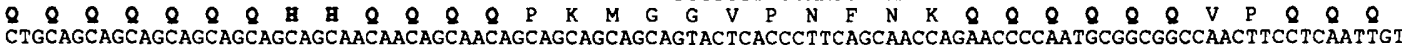

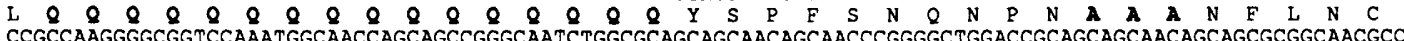

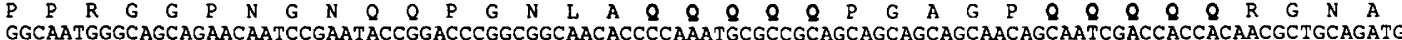
$\begin{array}{llllllllllllllllllllllllllllllllllll}G & N & G & Q & Q & N & N & P & N & T & G & P & G & G & N & T & P & N & A & P & Q & Q & Q & Q & Q & Q & Q & S & T & T & T & T & L & Q & M\end{array}$ Exon 5 -

AAGCAGACGCAGCAGTTGCACATTAGCCAGCAGGGTGGGGTGCTCAAGGTATTCAGGTGTCGGCTGGTCAGCATCTGCATTTGAGTGGCGACATGAAGAGCAAC

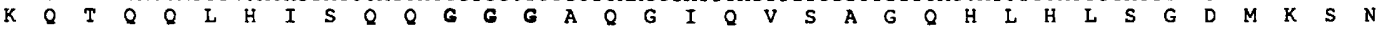
GTCTCGGTGGCCGCCCAGCAAGGTGTCTTCTTCAGTCAGCAGCAGGCGCAACAGCAACAGCAGCAGCAACAGCCTGGCGGCACCAACGGACCGAATCCCCAGCAG

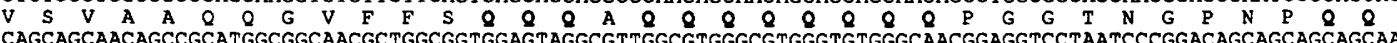

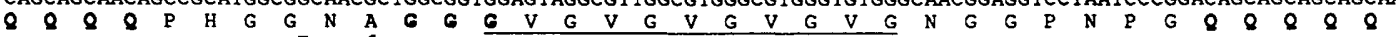
CCAAATCAAAACATGAGCAATGCAAATGTTCCCTCCGATGGCTTCTCGCTCTCCCAGAGCCAAAGCATGAACTTTAACCAGCAGCAGCAGCAACAGGCGGCCGCC

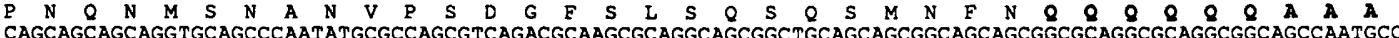

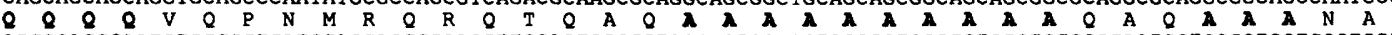

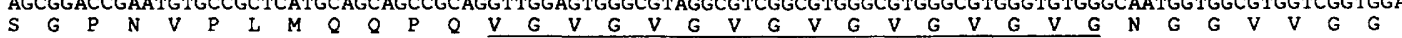
CCCGGTTCCGGTGGACCCAACAACGGTGCAATGAATCAGATGGGCGGACCCATGGGCGGCATGCCGGGCATGCAGATGGGTGGACCCATGAACCCGATGCAAATG $\begin{array}{lllllllllllllllllllllllllllllllllllll}P & G & S & G & G & P & N & N & G & A & M & N & Q & M & G & G & P & M & G & G & M & P & G & M & Q & M & G & G & P & M & N & P & M & Q & M\end{array}$ AACCCCAACGCTGCCGGTCCAACCGCCCAGCAGATGATGATGGGCAGCGGCGCTGGCGGACCGGGTCAGGTTCCGGGACCTGGCCAAGGACCAAATCCGAATCAA $\underset{\text { GCCAAGTTCCTGCAGCAGCAGCAGATGATGCGCGCCCAGGCGATGCAGCAACAGCAGCAGCACATGTCTGGAGCACGACCACCACCGCCCGAGTACAATGCCACC }}{\mathbf{P}} \mathbf{\mathbf { N }}$ A

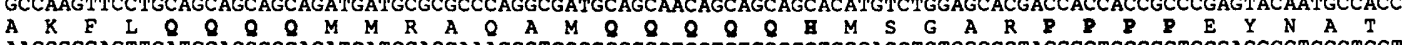

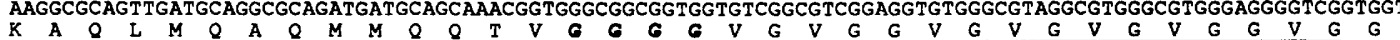
GCCAACGGTGGCCGCTTTCCGAACAGCGCTGCCCAGGCGGCGGCCATGCGGCGCATGACCCAGCAGCCCATACCGCCATCCGGTCCGATGATGCGACCACAGCAT

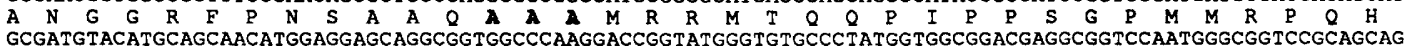

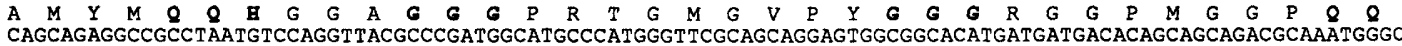

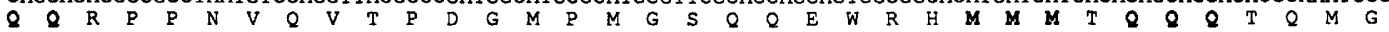

Figure 3. (See following page for rest of figure and legend.) 
Exon 7-

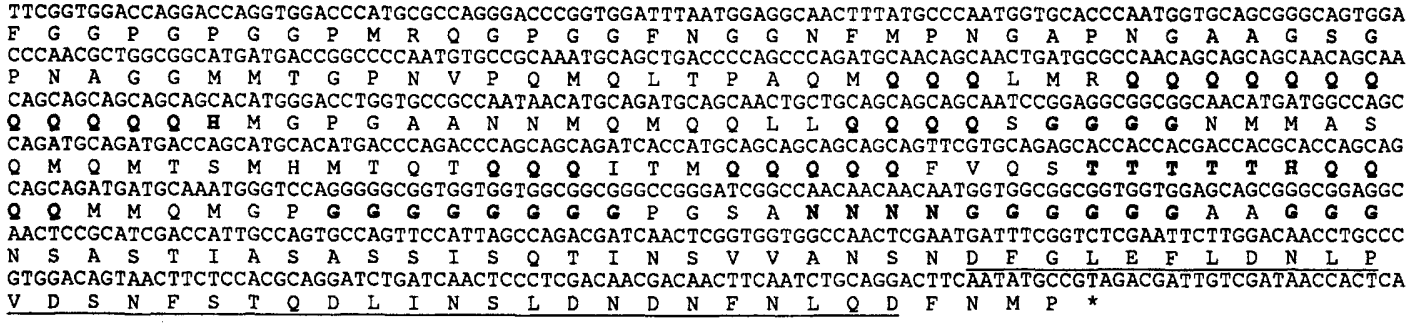

AACACCACCTCCAGCCAGCACCAAACATAACCACCATCACCACCATAACCACCACGATGTTGCCTCAGTTTTGTTTAGATTTTTTTTATTTTGTTGCCTCTTGTT GTTATTGGCCTGGACAGCCGAACCCAACCGACCCGACCTGACGCCCAACCGCCCCACACGGCCCCGCCCCCCTTGTTCCTGCCAACGAAGTTATTTTGTTTATTA TATGTGTGTGAATTTATTCCTAAGCTAAGTTCGTTCGTCTATGTACTCTAATTTCGTGGGCTCCACTGTATTTTATTGTATTGTATTGTATTTGATCGTATTTGT ATGTATTATTAGAGCTGTTCCCAAGGTCCAAGGCGAGCGGCCAATGGGCGTGGTAGAGGCGAGAGTTCGCAAAAGACATTCCATATGCAACGGTCGAACGAAGGA ATTAAAGAAATTCGAGAAAGTATTTGCAAGTACTTTGAAAACAATTGAACAGTTTTCAGATTCTCATACACCGATACAGATACAGATACTACAGACTCGTTGTGC AACTTAAGCACTTGTACTTAATGCAAAT'T TTAGTGCCACGCCCAGCGGATTGCACGCCCCATTTCGTTTGATTACTTAAGCAAAAACCAGATGAAATGATGGTA GCAAACACAAAAAGAACCAACAACAAAACAAAATCGAAAAACAAAACACAAAATAGTTGTACATTTTATATTATATTTAATTTAATTTAATTTTTATAAAAACAA AATCGACAAACTAAGAGAAACAAAAAAAAAAAA

ctaagagaacaacaaaaagcgaagaaaacaaaacaaaaaatgggaaacagatcgagaaactttcagaataaagagcaaaatattgg

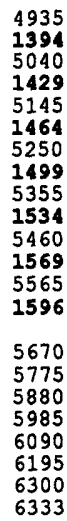

Figure 3. Nucleotide and predicted amino acid sequence of mam. The complete sequence of cDNA B4 (uppercase) and $5^{\prime}$ and $3^{\prime}$-flanking genomic sequences (lowercase) are presented. Both strands of the cDNA were sequenced and corroborated by sequencing the genomic exons. Approximately $4 \mathrm{~kb}$ of sequence derived from other cDNAs was determined to be identical to B4. Twenty regions showed differences between the genomic and cDNA sequence. This included 12 silent substitutions and four amino acid changes (residue 126, Ala to Thr; 326, Ala to Pro; 365, Gly to Asn; and $960 \mathrm{His}$ to Gln). The final four regions showed changes in the number of glutamine residues within homopolymer runs. Three cDNA regions were deleted for glutamine residues: region 69-84, three-residue deletion; region 651-664, two-residue deletion; region 765-777, four-residue deletion. One cDNA region contained two additional glutamine residues: region 392-396. These changes probably result from polymorphisms, because the cDNA and genomic templates were derived from different strains: cDNA, $d p c n b w$ (Brown and Kafatos 1988); genomic, Canton $S$ (Yedvobnick et al. 1988). The genomic region upstream of cDNA B4 contains a number of underlined sequences that resemble Drosophila consensus start sites and TATA boxes (Hultmark et al. 1986). Preliminary studies with primer extension analysis suggest that the first two putative start sites $(-87$ and -250$)$ are utilized. Putative polyadenylation signals in the $3^{\prime}$ cDNA and genomic sequence are indicated by underlines. Other cDNAs contain $\sim 1200$ bp of additional $3^{\prime}$-untranslated sequence and a poly(A) tail. The juncture between the seven exons of B4 are indicated by dashes above the sequence. Additionally, the limits of the 146-bp deletion associated with the mam allele HD $17 / 7$ and the insertion site of the P element in the mam allele HD 10/6 are indicated by dashes above the sequence. Regions rich in a particular amino acid are indicated in boldface type. Charge concentrations are underlined, and runs of alternating Gly-Val (GV) are double underlined.

proposed to serve as the translational start site; however, the sequences preceding the second ATG (position 1123, Fig. 3) conform better to the Drosophila consensus (Cavener 1987).

\section{The nucleotide sequence of $c D N A B 4$ predicts an unusual protein}

The nucleotide sequence of cDNA B4 and predicted amino acid sequence are presented in Figure 3 . The sequence contains a long ORF that shows excellent agreement with the Drosophila codon usage table compiled by M. Ashburner (Fig. 4A). A diagram summarizing the major domains within the protein is presented in Figure 4B.

An unusual feature of this protein is the large number of homopolymeric runs of amino acids, particularly polyglutamines. With five consecutive amino acids as the criterion for a homopolymer, there are 21 polyglutamine runs. The longest polyglutamine runs are 16 residues. There are four polyglycine runs $(10,7,8$, and 6 residues), three polyasparagine (5 residues each), one polyalanine (10 residues), and one polythreonine (5 residues). The homopolymers confer an atypical amino acid composition (Table 1 ). Nearly $22 \%$ of the protein is glutamine, compared to $5 \%$ for the average Drosophila protein. Glycine $(16.8 \%)$ and asparagine $(9.7 \%)$ are twice the average for Drosophila. Together, these three amino acids comprise $47 \%$ of the protein. The distribution of these residues suggests overall a highly polar, hydrophilic molecule. In contrast, the large nonpolar amino acid methionine $(5.1 \%)$ is abundant near the carboxyl end of the protein (residues 1125-1505) where 14\% of the protein is methionine. Proline $(7.7 \%)$ is also present at a higher than average frequency.

Apart from homopolymer runs, glycine is found as a doublet 47 times; these Gly-Gly doublets are distributed throughout the sequence with some concentrations (Fig. 4B). The glycine doublet is often followed by a proline residue $(24 \%)$ or other hydrophobic residue $168 \%$, including proline). Glycines are also distributed in runs alternating with valine. Between residues 986 and 1254, three Gly-Val runs are evident, consisting of 11,16 , and 17 amino acids.

A second notable feature of the protein is the number and distribution of charged amino acids (Fig. 4B). The protein has fewer charged residues $(8.3 \%)$ than an average Drosophila protein $(21.8 \%)$, discounting histidine. In mam histidine $(2.4 \%)$ is similar to an average 
Smoller et al.

Drosophila protein $(2.8 \%)$; however, the frequency of this residue may be influenced by its prevalence within opa $\langle\mathrm{CAX}|$ runs: the codons for histidine are CAT and CAC. Most of the histidine residues in mam (26/39) occur within polyglutamine regions. It is clear that regions of mam are rich in mixed charge, as well as in basic or acidic charges. Two regions of mixed charge concentration occur within residues 127-256 and 466-539. The former region also contains a predominantly basic area $(127-190)$ that is $30 \%$ arginine plus lysine, whereas the latter area also contains a predominantly acidic area $(466-534)$ that is $28 \%$ aspartic acid plus glutamic acid. A final concentration of acidic charges occurs at the carboxyl end (1559-1592), where $23 \%$ are negative. The charged domains are separated by numerous homopolymeric runs of amino acids (Fig. 4B). These runs contain little concentration of charge except, as noted above, for histidine residues interspersed within polyglutamine runs. Two regions, residues 1057-1194 and 1436-1558, contain virtually no charged or hydrophobic residues and may form long, randomly coiled structures.

The mam protein accumulates in the nucleus

Data base searches utilizing the mam sequence provided no definitive similarities to other proteins. The most significant matches were to proteins containing amino acid homopolymers. The prevalence of homopolymers in mam, in combination with its charge clusters, suggested some structural similarities to a large number of nuclear regulatory proteins (Brendel and Karlin 1989). Consequently, the mam protein was localized immunohistochemically, using mouse antibodies directed against mam fusion proteins. The sera recognized a predominant protein species on immunoblots in the size range predicted from the sequence analysis (Fig. 5A).

Initially, mam protein accumulation was observed in cell culture (Schneider's cell line S2). The coding region from CDNA B4 was cloned into the metallothionein-regulated expression vector, $\mathrm{pRmHa}-3$ (Bunch et al. 1988). This construct was transfected into cells and induced with copper. Cells were assayed for mam protein, utilizing mam antisera and fluorescein-conjugated secondary antibodies. In a small percentage of cells a strong nuclear signal was evident (Fig. 5B). To ensure that these cells were expressing the mam construct, a second clone that expresses $N$ (Fehon et al. 1990) was cotransfected. The cells expressing $N$ were identified using secondary antibodies conjugated to rhodamine. This demonstrated that cotransfected cells accumulated $N$ predominantly in the cytoplasm and membrane (Fig. 5C), as reported

Figure 4. (A) Analysis of ORFs within the sequence of cDNA B4. Solid bars denote ORFs that begin with methionine residues. The vertical positions of pixels above and below bars indicate the degree of similarity or dissimilarity, respectively, to a Drosophila codon usage table provided by $\mathrm{M}$. Ashburner, utilizing the GENEPRO program (Riverside Scientific). A single long ORF (4788 bp/1596 amino acid residues), evident in frame 3 , shows excellent agreement with Drosophila codon usage. $(B)$ Summary of major characteristics of the predicted B4 protein product. The horizontal bar represents the 1596-residue mam product with the regions of charge concentration highlighted. Above the bar are vertical hatch marks that indicate (1) the position of five or more identical amino acid residues, for glutamine $|Q|$, glycine $(\mathrm{G})$, asparagine $(\mathrm{N})$, alanine $(\mathrm{A})$, or threonine $(T)$; or $(2)$ the position of alternating Gly-Val (GV) runs; or (3) the position of Gly-Gly (GGX) doublets, which are not parts of longer glycine homopolymers, where $\mathrm{X}$ is usually a hydrophobic amino acid.

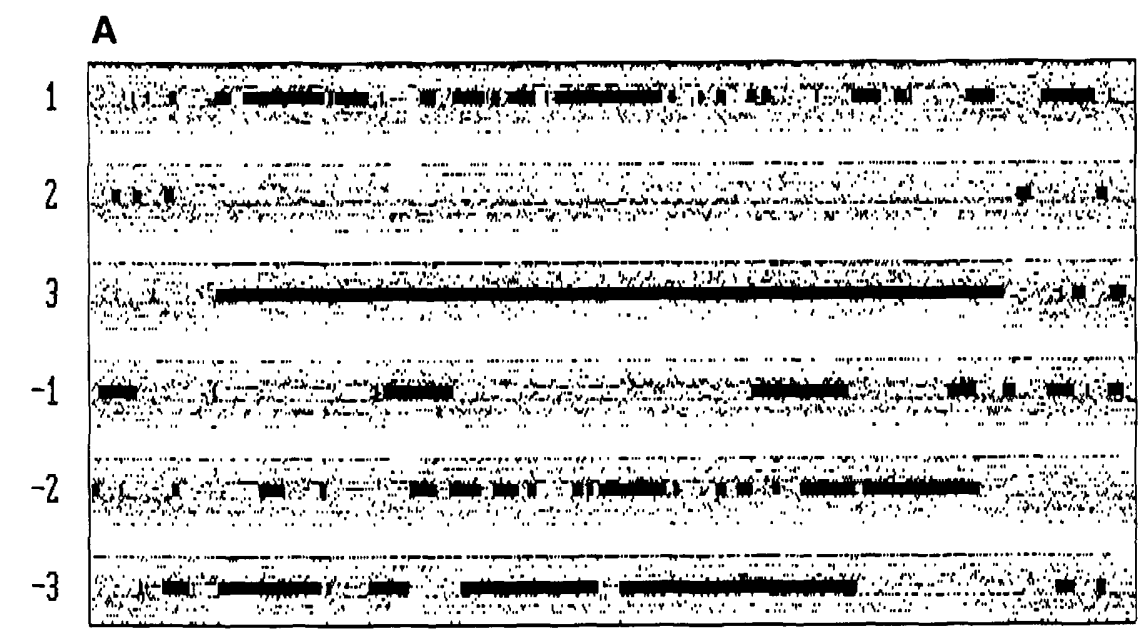

\section{B}

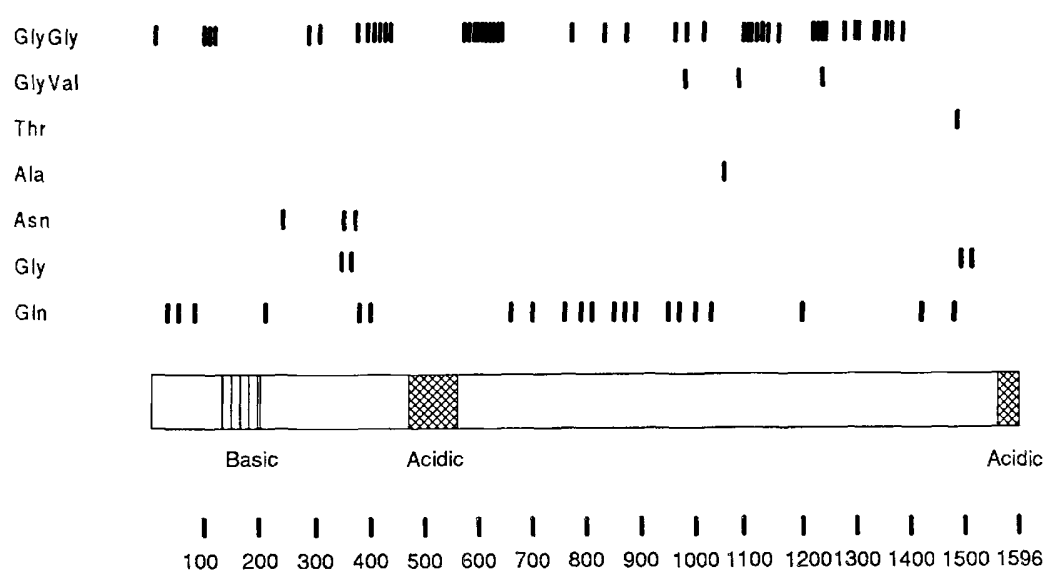


Table 1. Amino acid composition of predicted mam B4 product versus Drosophila

\begin{tabular}{lcccc}
\hline & mam (no.) & mam $(\%)$ & Drosophila $(\%)$ & Ratio $^{a}$ \\
\hline Gln (Q) & 347 & 21.7 & 5.0 & 4.3 \\
Gly (G) & 269 & 16.8 & 7.8 & 2.2 \\
Asn (N) & 155 & 9.7 & 4.6 & 2.1 \\
Pro (P) & 123 & 7.7 & 5.7 & 1.4 \\
Ala (A) & 108 & 6.7 & 7.8 & 0.9 \\
Met (M) & 82 & 5.1 & 2.4 & 2.1 \\
Leu (L) & 71 & 4.4 & 8.2 & 0.5 \\
Ser (S) & 71 & 4.4 & 7.6 & 0.58 \\
Val (V) & 64 & 4.0 & 6.0 & 0.67 \\
Thr (T) & 58 & 3.6 & 5.5 & 0.65 \\
Asp (D) & 42 & 2.6 & 5.1 & 0.51 \\
Phe (F) & 42 & 2.6 & 3.4 & 0.76 \\
His (H) & 39 & 2.4 & 2.8 & 0.86 \\
Arg (R) & 34 & 2.1 & 5.2 & 0.4 \\
Lys (K) & 34 & 2.1 & 5.3 & 0.4 \\
Glu (E) & 24 & 1.5 & 6.2 & 0.24 \\
Ile (I) & 18 & 1.1 & 4.7 & 0.23 \\
Tyr (Y) & 10 & 0.6 & 3.2 & 0.19 \\
Cys (C) & 4 & 0.2 & 2.3 & 0.09 \\
Trp (W) & 1 & 0.06 & 1.1 & 0.06 \\
Total & 1596 & & & \\
The & & &
\end{tabular}

${ }^{\text {aRatio }}=\operatorname{mam}(\%) /$ Drosophila $(\%)$. Drosophila data were calculated from the codon usage table compiled by M. Ashburner (unpubl.).

earlier (Fehon et al. 1990), and mam in the nucleus (Fig 5B). Similar results were obtained in cells cotranfected with plasmids expressing mam and $\beta$-galactosidase (data not shown).

To confirm that the nuclear accumulation of mam in cultured cells was significant, antisera were tested against whole mounts of early embryos. Staining of the cellular blastoderm $(\sim 3 \mathrm{hr}$ postfertilization) is presented in Figure 5D. As in the case of the S2 cells, the signal is predominantly nuclear. No regional accumulation of the protein within the embryo is evident at this stage.

\section{Discussion}

The neurogenic loci of Drosophila function during several developmental stages in numerous tissues and appear to mediate developmental cues that result in the segregation of apparently equipotent cells into different patterns of differentiation (Artavanis-Tsakonas 1988; Campos-Ortega 1988; Simpson 1990). Such processes are fundamental and may be regulated similarly in other systems (Yochem and Greenwald 1989). In an effort to understand the function of the mam locus in such processes, we have characterized its expression and determined the sequence of one of its products.

The mam locus comprises a $67-\mathrm{kb}$ transcription unit that codes for at least five transcripts accumulating over the first $16 \mathrm{hr}$ of embryogenesis (Fig. 2A, $\mathrm{A}^{\prime}$ ). A 6-kb, presumably maternal, transcript has been identified during the initial $2 \mathrm{hr}$ of development, consistent with the predictions of genetic studies (Jimenez and CamposOrtega 1982). Four zygotic transcripts are evident during the following $14 \mathrm{hr}$. Transcription from mam decreases significantly during later times until late larval/early pupal stages, when the transcripts reappear, correlated with the imaginal requirement for mam (Dietrich and Campos-Ortega 1984; Brand and Campos-Ortega 1990; $\mathrm{Xu}$ et al. 1990). Although the sequence differences between the transcripts have not yet been fully characterized, some of the variation appears to derive from alternative $3^{\prime}$ and $5^{\prime}$ ends (see legend to Fig. 3), and it is clear that the larger transcripts contain most or all of the sequence identified in cDNA B4 (C. Friedel, unpubl.).

Utilizing a probe that recognizes the five transcripts, the spatial pattern of transcript accumulation was observed during neurogenesis (Fig. 2B,C). The transcripts appear ubiquitous in germ-band-extended embryos, a stage that contains segregating neuroblasts. This suggests that mam transcription is not limited to a particular cell type during this process. During later embryogenesis, when the ventral cord and brain are condensed, it is clear that mam transcription predominates in the CNS, as predicted from the enhancer trap studies of Bier et al. (1989). It appears that the territories of mam transcription during embryogenesis overlap significantly with those reported for $N$ (Hartley et al. 1987), Dl (Vassin et al. 1987; Kopczynski et al. 1989), and particular products of the $E$ (spl) region (Knust et al. 1987;
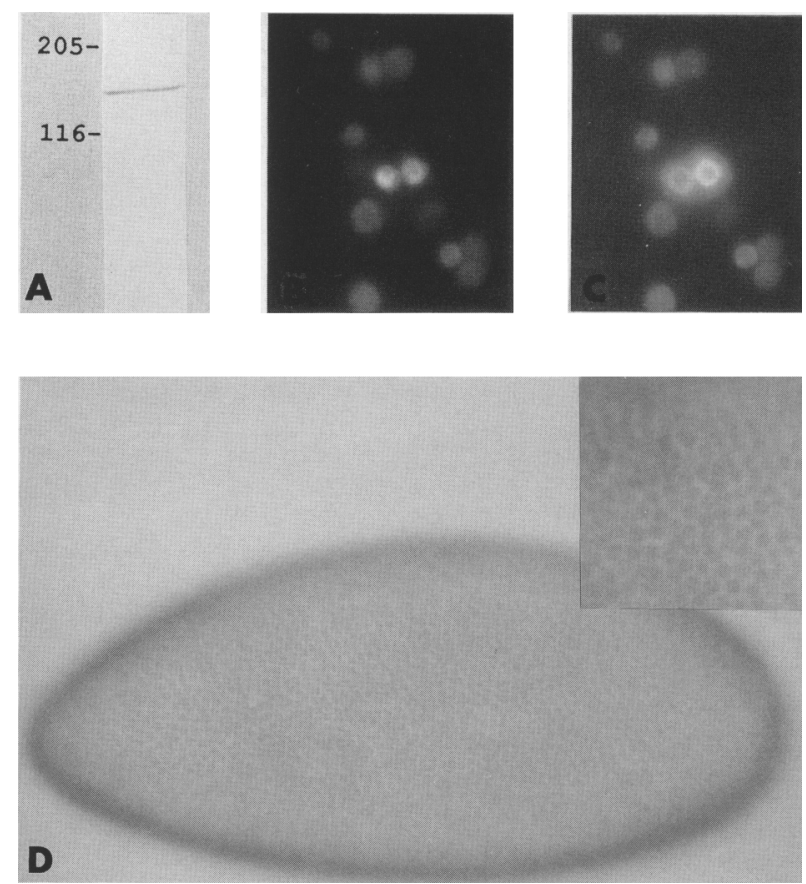

Figure 5. Immunolocalization of mam. (A) Antisera raised against mam fusion proteins recognize a single protein on immunoblots of embryonic proteins (8- to 24-hr embryos), in the size range predicted from the DNA sequence. Size standards, $205 \mathrm{kD}$ (myosin) and $116 \mathrm{kD}$ ( $\beta$-galactosidase). ( $B$ and $C) . \mathrm{Im}$ munolocalization of mam protein $(B)$ or $N$ protein $(C)$ in cotransfected Schneider's S2 cells, expressing products under the control of a metallothionein promoter. $N$ and mam proteins were visualized by utilizing secondary antibodies conjugated to rhodamine and fluorescein, respectively. (D) Immunolocalization of mam in nuclei of blastoderm embryos. 
Hartley et al. 1988) and bib (Rao et al. 1990). The sites of postembryonic mam accumulation, expected to include imaginal disk tissue, are presently under investigation. $N$ and mam function are required for developmental decisions in the eye and wing, etc. (Shellenbarger and Mohler 1978; Dietrich and Campos-Ortega 1984; Cagan and Ready 1989), and genetic interaction data (Brand and Campos-Ortega 1990; Xu et al. 1990) predict that products of mam and $N$ will accumulate together in several imaginal tissues. $N$ is expressed in these tissues (Johansen et al. 1989; Kidd et al. 1989; Markopoulou and Artavanis-Tsakonas 1989).

In screens for cDNAs, the largest isolated, B4, was derived from 8- to 12-hr embryos and measures $6.3 \mathrm{~kb}$. The cDNA sequence (Fig. 3) demonstrated a single ORF with a codon usage similar to other Drosophila genes (Fig. 4A). Nearly half the mass of the predicted B4 product derives from three amino acids, glutamine, asparagine, and glycine, and many of the residues are contained in homopolymer runs. The presence of homopolymers in nuclear proteins of Drosophila was noted several years ago (Laughon et al. 1985), and the list is now quite long, including zeste (Pirrotta et al. 1987), cut (Blochinger et al. 1988), engrailed (Poole et al. 1985), and Deformed (Regulski et al. 1987), to cite just a few. The list is not limited to Drosophila, as yeast regulatory proteins contain similar repeats, that is, ADR6 (O'Hara et al. 1988) and HAP2 (Pinkham et al. 1987), and certain mammalian regulatory proteins as well [i.e., mouse glucocorticoid receptor (Danielsen et al. 1986)].

Another common characteristic of nuclear proteins is regions of alternating amino acids, such as alanine/glutamine runs in single-minded (Crews et al. 1988) and zeste (Pirrotta et al. 1987). The mam sequence has three very uncommon runs of alternating glycine/valine residues. Interestingly, such runs have also been observed in the homeo-domain-containing protein orthodenticle (Finkelstein et al. 1990), Ultrabithorax of Drosophila pseudo-obscura (Wilde and Akam 1987), and herpes simplex virus immediate early protein (Perry et al. 1986).

The function of homopolymeric and alternating runs of amino acid in proteins is still conjecture. Although common in DNA-binding proteins, they are also found outside this class of molecules and may play a generic role, as a spacer or hinge between other protein domains (Beachy et al. 1985; Laughon et al. 1985). The presence of such domains in transcriptional activators might be consistent with the role of a protein in binding both DNA and other regulatory proteins simultaneously. For example, regions devoid of charged or hydrophobic residues may form random coils that provide flexibility to tertiary conformation (Brendel and Karlin 1989). Alternatively, it is conceivable that some proportion of these repeated domains is functionless and derives from processes such as genomic drive. Evolutionary comparisons between genes containing homopolymers, such as polyglutamine, have shown these regions to have high rates of sequence variation (Kassis et al. 1986; Treier et al. 1989|, consistent with this interpretation. In mam, pre- liminary comparisons between the sequence in Drosophila melanogaster and Drosophila virilis also reveal high rates of change within these regions (S. Newfeld and B. Yedvobnick, in prep.). These ideas are not mutually exclusive, and one can imagine that a mechanism promoting variability in the spacing between functional protein domains would be beneficial.

In one case, a function for a polyglutamine-rich region has been reported. The DNA-binding protein Spl apparently contains glutamine-rich transcriptional activation domains. Furthermore, it appears that a polyglutamine region from the Antennapedia protein, when coupled to the DNA-binding domain of Spl, can effect transcriptional activation (Courey et al. 1989). In Spl the glutamine-rich regions are in close proximity to serinethreonine-rich regions; it is of potential interest that a similar arrangement of residues is found at two locations in the mam sequence (residues 890-920 and 1469-1504).

A second feature of the mam protein common to many nuclear proteins is the clustered distribution of charged amino acid residues. Although there is very little charge overall in mam, the basic and acidic residues reside, for the most part, in three areas (Figs. 3 and 4B). Similar charge concentrations have been described in a number of transcriptional activators (Brendel and Karlin 1989|, such as GAL4, where the basic DNAbinding domain is distinct from an acidic activation domain (Fischer et al. 1988), as well as the DNA-binding protein zeste (Pirrotta et al. 1987).

Antisera directed against mam fusion proteins was utilized to identify the site of protein accumulation. In cultured cells transfected with a plasmid that expresses large quantities of mam, it appears that the protein localizes preferentially within the nucleus; in contrast, the same cells accumulate $N$ in the cytoplasm and membrane when cotransfected (Fig. 5B,C). Finally, the mam antisera stain the nuclei of embryonic blastoderm cells (Fig. 5D), further suggesting that this is the site of action. However, mam contains no obvious canonical motifs associated with many nuclear proteins (e.g., homeo domain, zinc finger, leucine zipper, helix-loophelix, etc.). Consequently, if it functions as a transcriptional regulator, it may contain currently undescribed protein domains involved in such processes. It is also conceivable that an alternative transcript of mam encodes a related polypeptide that contains a more common motif of nuclear proteins.

The amino acid sequence and nuclear localization of the mam protein suggest a regulatory function. Although the precise role of mam in the neurogenic pathway remains to be established, the coincident expression patterns and genetic interactions of mam and $N$ suggest two principal hypotheses. mam may influence the expression of $N$ directly or indirectly, or, alternatively, $N$ may affect the activity of the mam protein. A critical consideration in regard to these hypotheses is whether the interactions observed between these genes are compatible with the notion of nuclear regulation or whether they are more consistent with the idea of phys- 
ical interactions between mam and $N$ proteins, which presumably could occur in the cytoplasm. The available data does not allow a clear resolution between these choices.

Alleles of $N$ with mutations in either the extracellular epidermal growth factor (EGF)-like domain, $A x$ and $s p l$ (Hartley et al. 1987, Kelley et al. 1987), or the intracellular domain, $n d, n d^{2}$ (Xu et al. 1990), demonstrate interactions with mam. The observation that these interactions are not mam allele specific suggests that the dosage of mam can influence the phenotypic expression of a variety of $N$ alleles. In a hypothetical pathway, where mam is involved in the regulation of $N$ expression, a number of mechanisms are feasible that could explain these interactions. A simple model suggests that particular lesions of $N$ lower or elevate the activity of the protein and that reduced concentration of a potential regulator (mam) further affects phenotype through changes in the number of $N$ molecules.

An alternative hypothesis proposes that particular genetic interactions between mam and $N$ reflect the physical interactions of their products. In the absence of any knowledge of the molecular nature of the mam product, Xu et al. (1990) suggested that $N, D l$, and mam may participate in a molecular assembly where proper dosage of each component is critical for function. A similar argument was raised by Brand and Campos-Ortega (1990) following a genetic screen that uncovered an interaction between mam and $N$. For the case of $N$ and $D l$ proteins, there is very convincing biochemical evidence for physical interactions (Fehon et al. 1990). Our observation that the mam protein resides predominantly in the nucleus does not exclude such interactions. For example, it is conceivable that mam resides transiently in the cytoplasm after its synthesis. This could provide the opportunity for the mam protein to interact with the cytoplasmic domain of $N$ prior to relocating to the nucleus, in a manner similar to the proposed roles of Toll and dorsal (Hashimoto et al. 1988; Roth et al. 1989; Rushlow et al. 1989; Steward 1989). In this regard, it is interesting that the lesions in the $n d$ and $n d^{2}$ proteins are in the intracellular domain of the $N$ molecule (Xu et al. 1990). In this model, interactions between mam and the $\mathrm{N}$ alleles containing perturbations in the extracellular EGF domain $\mid A x$ and $s p l\rangle$ would require that changes in this extracellular region influence the function of the intracellular domain. The molecular probes are now available to test the predictions of such hypotheses.

\section{Methods}

\section{Isolation of revertants}

The mam allele HD 10/6 contains a 1.6-kb P element in exon 1 of cDNA B4 (Fig. 1). To revert this allele, HD 10/6 males (balanced over $\mathrm{CyO}$ ) were mass-mated to an $\mathrm{M}$ strain containing the second chromosome balancers $\mathrm{Pm}$ and $\mathrm{Cy}$. Groups of HD $10 / 6 / C y \mathrm{~F}_{1}$ males were then mated to a mam tester allele (balanced over $\mathrm{CyO}$, and the progeny were scored for straightwinged survivors. From $17,000 \mathrm{~F}_{2}$ progeny, two revertants were isolated. The revertant chromosomes were made homozygous and analyzed as described previously.

\section{Nucleic acids}

The isolation of DNA and RNA, blotting analyses, and the preparation of genomic libraries from mutant DNAs were performed as described previously (Yedvobnick et al. 1988).

\section{Isolation of cDNA clones}

Several embryonic cDNA libraries in a plasmid vector were supplied by Nick Brown (Harvard University); the libraries were screened by using a high-density filter screening protocol (Brown and Kafatos 1988). In some cases, pools of $\sim 30,000$ clones were miniprepped and screened on Southern blots to identify smaller populations of clones for filter screening. A typical blot contained 20 lanes, totaling $\sim 600,000$ individual cDNAs. The initial oligonucleotide probes for mam cDNAs were derived from the DNA sequence surrounding three opa elements (see Fig. 1), and subsequent probes were derived from unique exonic sections of various cDNAs. CDNAs were mapped across the mam chromosomal region under very high stringency conditions to eliminate cross-hybridization due to repetitive elements. Typically, standard hybridization conditions [ $5 \times$ SSC, $\left(0.75 \mathrm{M} \mathrm{NaCl}, 0.075 \mathrm{M} \mathrm{Na}_{3} \mathrm{C}_{6} \mathrm{H}_{5} \mathrm{O}_{7} 50 \%\right.$ formamidel at $42^{\circ} \mathrm{C}$ were followed by high-temperature $\left(80^{\circ} \mathrm{C}\right)$ washes in $0.1 \times$ SSC, $0.1 \%$ SDS. The largest cDNA isolated, B4, was chosen for DNA sequencing.

\section{DNA sequencing}

A shotgun library derived from the sonication of CDNA B4 was constructed in M13, as described by Bankier and Barrell (1983). The sequence of 60 clones produced $\sim 65 \%$ of the sequence. The remainder of the sequence of both strands of cDNA B4 was derived from subclone templates and specific priming of templates with synthetic oligonucleotides. Additionally, the sequence of smaller versions of cDNA B4, totaling $\sim 4000 \mathrm{bp}$, was obtained. Similar strategy was utilized to sequence the corresponding genomic regions, although only a single strand was determined. Standard dideoxy sequencing reactions utilized modified T7 DNA polymerase (Sequenase, U.S. Biochemicals). Sequences were compiled and analyzed by utilizing the Staden Program (Staden 1986) and GENEPRO (Riverside Scientific).

\section{In situ RNA localization}

Tissue sections were prepared according to Ingham et al. (1985), with the following modifications. Embryos were collected in mesh baskets with $\mathrm{NaCl} /$ Triton rinses $(0.03 \% \mathrm{NaCl}, 0.4 \%$ Triton X-100), dechorionated in full-strength bleach for $3 \mathrm{~min}$ with gentle agitation, rinsed with $\mathrm{NaCl} /$ Triton and fixed in heptane/paraformaldehyde fixative, $1: 1$, by rapid shaking for 30 min (Harding et al. 1986). Paraformaldehyde fixative consisted of $4 \%$ paraformaldehyde in phosphate-buffered saline [PBS: $0.13 \mathrm{M} \mathrm{NaCl}, 0.007 \mathrm{M} \mathrm{Na}_{2} \mathrm{HPO}_{4}, 0.003 \mathrm{M} \mathrm{Na}_{2} \mathrm{HPO}_{4}$ (pH 8.0 )l, $40 \%$ DMSO; paraformaldehyde was freshly prepared. After removal of the vitelline membranes (Mitchison and Sedat 1983), the embryos were rehydrated through ethanol $(100,95$ $90,70,50$, and $30 \%$ ) and postfixed in $4 \%$ paraformaldehyde in PBS. Embryos were then dehydrated through the same ethanol series, embedded in paraffin and sectioned to $5 \mu \mathrm{m}$. The sections were collected on slides, coated with poly-D-lysine [50 $\mu \mathrm{g} / \mathrm{ml})$ in $10 \mathrm{mM}$ Tris- $\mathrm{HCl}(\mathrm{pH} 8.0)]$ and stored overnight at $45^{\circ} \mathrm{C}$. Slides were dewaxed in xylene /two incubations, $10 \mathrm{~min}$ each) and rehydrated through ethanol $(100,95,80,60$, and $30 \%$ PBS, 2 min each). They were then incubated in $0.2 \mathrm{~N} \mathrm{HCl}$ for 20 $\mathrm{min}$ at room temperature, rinsed $30 \mathrm{sec}$ in distilled water, and incubated at $70^{\circ} \mathrm{C}$ in $2 \times \mathrm{SSC}$ for $30 \mathrm{~min}$. The sections were then treated with Pronase $[0.5 \mathrm{mg} / \mathrm{ml}$ in $50 \mathrm{~mm}$ Tris-Cl $(\mathrm{pH}$ 7.5), $5 \mathrm{~mm}$ EDTA] for $10 \mathrm{~min}$ at room temperature, incubated $30 \mathrm{sec}$ in $0.2 \mathrm{mg} / \mathrm{ml}$ glycine in PBS, rinsed twice in PBS for 3 
min, and fixed in $4 \%$ paraformaldehyde in PBS for $20 \mathrm{~min}$ at room temperature. The slides were treated with $0.5 \%(\mathrm{vol} / \mathrm{vol})$ acetic anhydride in $0.1 \mathrm{M}$ triethanolamine $(\mathrm{pH} 8.0)$, dehydrated, and air-dried.

Single-strand RNA probes were synthesized according to Hartley et al. (1987), except that the transcription reaction proceeded at $37^{\circ} \mathrm{C}$ for $30 \mathrm{~min}$.

Hybridizations, rinses, and autoradiography were performed according to Ingham et al. (1985). Coverslips were sealed onto slides with rubber cement, and slides were hybridized upright in a humid chamber. NTB2 autoradiographic emulsion was diluted $1: 1$ with sterile distilled water. After autoradiography, slides were stained with Giemsa $\left[5 \%(\mathrm{vol} / \mathrm{vol})\right.$ in $0.01 \mathrm{M} \mathrm{NaPO}_{4}$ buffer (pH 6.8)], rinsed twice in distilled water, air-dried, and viewed under oil.

\section{Immunohistochemistry}

Antisera were produced against two mam fusion proteins. A 366-bp restriction fragment, inserted into the pUR 291 vector (Ruther and Muller-Hill 1983) produced a fusion of 122 amino acids of mam (residues 511-632; see Fig. 3) to $\beta$-galactosidase. A 3963-bp restriction fragment inserted into the pGEX3 vector (Smith and Johnson 1988) produced 1321 amino acids of mam (residues 245-1565; see Fig. 3) fused to glutathione-S-transferase. Both fusion proteins were purified as insoluble aggregates (Carroll and Laughon 1987) and injected into mice at 3- to 4-week intervals using $50 \mu \mathrm{g}$ of protein in Maalox with $3 \times 10^{9}$ killed pertussis organisms per dose (R. Hunter, pers. comm.). Useful antisera were obtained after four to five injections. The 122-amino-acid segment contains no repetitive sequences, and its antisera recognizes a single immunoblot band in 0 - to $24-\mathrm{hr}$ embryos. Antisera to the 1321 -amino acid segment were preadsorbed to $D$. virilis embryos and produce an identical immunoblot pattern (data not shown). Both sera show qualitatively similar patterns of staining on cultured cells and embryos. All antisera were precipitated with an equal volume of saturated ammonium sulfate solution and resuspended in PBS with $0.02 \%$ sodium azide.

For immunoblots, $100 \mu \mathrm{g}$ of embryos was collected in Trisbuffered saline $(0.3 \mathrm{M} \mathrm{NaCl}, 0.01 \mathrm{M}$ Tris $)$ with $0.5 \%$ Triton $\mathrm{X}-100$ (TBST), dechorionated in $50 \%$ bleach, rinsed with TBST twice, and frozen in liquid nitrogen. The embryos were homogenized in $300 \mu \mathrm{l}$ of $2 \times$ Laemmli buffer, boiled for $5 \mathrm{~min}$, and microfuged for $5 \mathrm{~min}$. The supernatant was transferred to a new tube, and $20 \mu \mathrm{l}$ was loaded onto a $7.5 \%$ SDS-polyacrylamide gel for electrophoresis and transfered to a nitrocellulose filter. The filter was stained with Ponceau $S$ to assure transfer. After staining, the filter was incubated with anti-mam antiserum at $1: 3000$ dilution in TBST $/ 5 \%$ dry milk, overnight at $4^{\circ} \mathrm{C}$. The filter was rinsed three times, followed by two 5 -min washes. The filter was then incubated with goat anti-mouse IgG (GAM) antibodies linked to horseradish peroxidase (HRP) for $2 \mathrm{hr}$ at $4^{\circ} \mathrm{C}$ (Jackson Immunoresearch). After washing as above, the filter was stained in $0.1 \mathrm{M}$ diaminobenzidine (DAB), $0.0015 \%$ $\mathrm{H}_{2} \mathrm{O}_{2}$.

For whole mounts, embryos were collected in TBST, dechorionated in $50 \%$ bleach, and rinsed twice in TBST and twice in water. Embryos were fixed in $10 \mathrm{ml}$ each of fresh $4 \%$ paraformaldehyde and heptane and shaken vigorously for $30 \mathrm{~min}$ at room temperature. Paraformaldehyde was removed and replaced with an equal volume of methanol and shaken vigorously for 15-20 sec by hand. Liquid phases and embryos at the interface (which have not lost their vitelline membranes) were removed. Embryos were rinsed three times with methanol, transferred to an Eppendorf tube, and rinsed three times with PBS. Embryos were blocked for $30 \mathrm{~min}$ to $1 \mathrm{hr}$ in PBS, $0.1 \%$ Triton X-100 (PBST) with $10 \%$ normal goat serum (NGS), and rinsed once with PBS and incubated overnight in primary antiserum diluted $1: 1000$ in PBST with $10 \%$ NGS. Primary serum was removed, and embryos were rinsed three times in PBS, followed by a $30-\mathrm{min}$ wash in PBST with $10 \%$ NGS. The embryos were then incubated for $2 \mathrm{hr}$ at $4^{\circ} \mathrm{C}$ in secondary antibodies (GAM/HRP), PBST with $1 \%$ NGS. This was followed by three rinses in PBS and a 30-min wash in PBST with $1 \%$ NGS. After a final rinse in PBS, $350 \mu \mathrm{l}$ of PBS was added, followed by $20 \mu \mathrm{l}$ of $10 \mathrm{mg} / \mathrm{ml} \mathrm{DAB}$ with mixing. One microliter of $3 \% \mathrm{H}_{2} \mathrm{O}_{2}$ was added and mixed thoroughly by inversion. The embryos were allowed to develop for 2-5 min. The reaction was stopped by the removal of the DAB solution and the addition of $70 \%$ ethanol. The embryos were then rinsed twice more in $70 \%$ ethanol and three times in $100 \%$ ethanol. After addition of methylsalicylate, the embryos were mounted (Entellan).

\section{Cell culture}

All culture methods are as described (Fehon et al. 1990). S2 cells were grown in M3 media with $11 \%$ fetal bovine serum, 100 $\mathrm{U} / \mathrm{ml}$ penicillin, and $100 \mu \mathrm{g} / \mathrm{ml}$ streptomycin. Five milliliters of log-phase cells was transfected with $20 \mu \mathrm{g}$ metallothioncin plasmid DNAs (Bunch et al., 1988) as a calcium phosnhate precipitate in $1 \mathrm{ml}$. The cells were left under the DNA precipitate for $16-18 \mathrm{hr}$, washed once with complete me.lium, and allowed to rest for $24 \mathrm{hr}$ before induction with $0.7 \mathrm{~mm}$ copper sulfate. After $24 \mathrm{hr}$, cells were collected by centrifugation, washed in PBS, and fixed in 2\% paraformaldehyde for 10-15 min at room temperature. Cells were then centrifuged, rinsed twice in PBS, and incubated for $1 \mathrm{hr}$ in primary antiserum in PBS with $0.1 \%$ saponin and $1 \%$ NGS (PSN). Mouse anti-mam antiserum was used at $1: 1000$, and affinity purified rabbit anti-Notch antiserum (provided by the Artavanis lab) was used at $1: 500$. After washing once in PBS, cells were incubated in double-labeling grade secondary antibodies (Jackson) linked to flourescein or rhodamine, for mam or Notch, respectively. Secondary antibodies were diluted $1: 250$ in PSN. Cells were then rinsed twice in PBS and mounted in $90 \%$ glycerol, $10 \% 1 \mathrm{M}$ Tris $1 \mathrm{pH}$ 8.0 ), and $0.5 \% n$-propyl-gallate. Cells were photographed under epifluorescence.

\section{Acknowledgements}

We are extremely grateful to Guy Benian and Steve L'Hernault for their advice during various aspects of this study; to numerous people for analyzing the sequence, particularly Russell Doolittle, Keith Wilkinson, Roger Clerc, Sam Karlin, and Volker Brendel; to Nick Brown and Kai Zinn for supplying cDNA libraries, to the Artavanis-Tsakonas lab, especially Rick Fehon, for hands on assistance with immunohistochemistry; to the Levine lab for assistance with RNA localization; to the Campos-Ortega and Jan labs for supplying several new mam alleles; to Michael Ashburner for providing the codon usage table; to Stuart Newfeld, Guy Benian, Steve L'Hernault, Vicky Finnerty, Gray Crouse, and Sue Jinks-Robertson for comments on the manuscript; and to Jacqueline Balthazar for technical assistance. This work was supported by the American Cancer Society. D.S. and D.B. received support from Sigma Xi.

Sequence data described in this paper have been submitted to the EMBL/GenBank Data Libraries under accession number X54251.

The publication costs of this article were defrayed in part by payment of page charges. This article must therefore be hereby marked "advertisement" in accordance with 18 USC section 1734 solely to indicate this fact.

\section{References}

Artavanis-Tsakonas, S. 1988. The molecular biology of the 
Notch locus and the fine tuning of differentiation in Drosophila. Trends Genet 4: 95-100.

Bankier, A.T. and B.G. Barrell. 1983. In Techniques in the life sciences, (ed. R.A. Flavell), vol. B508, pp. 1-34. Elsevier, Ireland.

Beachy, P.A., S.L. Helfand, and D.S. Hogness. 1985. Segmental distribution of bithorax complex proteins during Drosophila development. Nature 313: 545-551.

Bier, E., H. Vaessin, S. Shepherd, K. Lee, K. McCall, S. Barbel, L. Ackerman, R. Carretto, T. Uemura, E. Grell, L.Y. Jan, and Y.N. Jan. 1989. Searching for pattern and mutation in the Drosophila genome with a P-lacZ vector. Genes Dev. 3: $1273-1287$.

Blochinger, K., R. Bodmer, J. Jack, L.Y. Jan, and Y.N. Jan. 1988. Primary structure and expression of a product from cut, a locus specifying sensory organ identity in Drosophila. Nature 333: 629-635.

Brand, M. and J.A. Campos-Ortega. 1990. Second site modifiers of the split mutation of Notch define genes involved in neurogenesis in Drosophila melanogaster. Wilhelm Roux's Arch. Dev. Biol. 198: 275-285.

Brendel, V. and S. Karlin. 1989. Association of charge clusters with functional domains of cellular transcription factors. Proc. Natl. Acad. Sci. 86: 5698-5702.

Brown, N.H. and F.C. Kafatos. 1988. Functional cDNA libraries from Drosophila embryos. J. Mol. Biol. 203: 425-437.

Bunch, T.A., Y. Grinblat, and C.S.B. Goldstein. 1988. Characterization and use of the Drosophila metallothionein promoter in cultured Drosophila melanogaster cells. Nucleic Acid Res. 16: 1043-1061.

Cagan, R.L. and D.F. Ready. 1989. Notch is required for successive cell decisions in the developing Drosophila retina. Genes Dev. 3: 1099-1112.

Campos-Ortega, J.A. 1988. Cellular interactions during neurogensis of Drosophila melanogaster. Trends Neurosci. 11: 400-405.

Carroll, S.B. and A. Laughon. 1987. Production and purification of polyclonal antibodies to the foreign segment of $\beta$-galactosidase fusion proteins. In DNA cloning, (ed. D.M. Glover), vol. III. IRL Press, Oxford.

Cavener, D. 1987. Comparison of the consensus sequence flanking translational start sites in Drosophila and vertebrates. Nucleic Acid Res. 15: 1353-1361.

Courey, A.J., D.A. Holtzman, S.P. Jackson, and R. Tjian. 1989. Synergistic activation by the glutamine-rich domains of human transcription factor Spl. Cell 59: 827-836.

Crews, S.T., J.B. Thomas, and C.S. Goodman. 1988. The Drosophila single-minded gene encodes a nuclear protein with sequence similarity to the per gene product. Cell 52: 143-151.

Danielson. M., J.P. Northrop, and G.M. Ringold. 1986. The mouse glucocorticoid receptor: Mapping of functional domains by cloning, sequencing and expression of wild type and mutant receptor proteins. EMBO I. 5: 2513-2522.

de la Concha, A., V. Dietrich, D. Weigel, and J.A. Campos-Ortega. 1988. Functional interactions of neurogenic genes of Drosophila melanogaster. Genetics 118: 499-508.

Dietrich, U. and J.A. Campos-Ortega. 1984. The expression of neurogenic loci in imaginal epidermal cells of Drosophila melanogaster. J. Neurog. 1: 315-332.

Doe, C.Q. and C.S. Goodman. 1985a. Early events in insect neurogenesis. I. Development and segmental differences in the pattern of neuronal precursor cells. Dev. Biol. 111: 193205.

- 1985b. Early events in insect neurogenesis. II. The role of cell interactions and cell lineage in the determination of neuronal precursor cells. Dev. Biol. 111: 206-219.

Fehon, R.G., P.J. Kooh, I. Rebay, C.C. Regan, T. Xu, M.A.T.
Muskavitch, and S. Artavanis-Tsakonas. 1990. Molecular interactions between the protein products of the neurogenic loci Notch and Delta, two EGF-homologous genes in Drosophila. Cell 61: 523-534.

Finkelstein, R., D. Smouse, T.M. Capaci, A.C. Spradling, and N. Perrimon. 1990. The orthodenticle gene encodes a novel homeo domain protein involved in the development of the Drosophila nervous system and ocellar visual structure. Genes Dev. 4: 516-527.

Fischer, J.A., E. Giniger, T. Maniatis, and M. Ptashne. 1988. GAL4 activates transcription in Drosophila. Nature 332: $853-856$

Harding, K., C. Rushlow, H.J. Doyle, T. Hoey, and M. Levine. 1986. Cross-regulatory interactions among pair-rule genes in Drosophila. Science 233: 953-959.

Hartenstein, V. and J.A. Campos-Ortega. 1984. Early neurogenesis in wild-type Drosophila melanogaster. Wilhelm Roux's Arch. Dev. Biol. 193: 308-325.

- 1986. The peripheral nervous system of mutants of early neurogenesis in Drosophila melanogaster. Wilhelm Roux's Arch. Dev. Biol. 195: 210-221.

Hartley, D.A., A. Preiss, and S. Artavanis-Tsakonas. 1988. A deduced gene product from the Drosophila neurogenic locus, Enhancer of split, shows homology to mammalian Gprotein $\beta$-subunit. Cell 55: 785-795.

Hartley, D.A., T. Xu, and S. Artavanis-Tsakonas. 1987. The embryonic expression of the Notch locus of Drosophila mela nogaster and the implications of point mutations in the extracellular EGF-like domain of the predicted protein. EMBO J. 6: 3407-3417.

Hashimoto, C., K.L. Hudson, and K.V. Anderson 1988. The Toll gene of Drosophila, required for dorsal-ventral embryonic polarity, appears to encode a transmembrane protein. Cell 52: $269-279$.

Hoppe, P.E. and R.J. Greenspan. 1990. The Notch locus of Drosophila is required in epidermal cells for epidermal development. Development (in press).

Hultmark, D., R. Klemenz, and W.J. Gehring 1986. Translational and transcriptional control elements in the untranslated leader of the heat-shock gene hsp22. Cell 44: 429-438.

Ingham, P.W., K.R. Howard, and D. Ish-Horowitz. 1985. Transcription pattern of the Drosophila segmentation gene hairy. Nature 318: 439-445.

Jimenez, F. and J.A. Campos-Ortega. 1982. Maternal effects of zygotic mutants affecting early neurogenesis in Drosophila. Wilhelm Roux's Arch. Dev. Biol. 191: 191-201.

Johansen, K.M., R.G. Fehon, and S. Artavanis-Tsakonas. 1989. The Notch gene product is a glycoprotein expressed on the cell surface of both epidermal and neuronal precursor cells during Drosophila development. I. Cell Biol. 109: 24272440.

Kassis, J.A., S.J. Poole, D.K. Wright, and P.H. O'Farrell. 1986. Sequence conservation in the protein coding and intron regions of the engrailed transcription unit. $E M B O F$. 5: 35833589.

Kelley, M.R., S. Kidd, W.A. Deutsch, and M.W. Young 1987. Mutations altering the structure of epidermal growth factorlike coding sequences at the Drosophila Notch locus. Cell 51: 539-548.

Kidd, S., M.R. Kelley, and M. Young. 1986. Sequence of the Notch locus of Drosophila melanogaster: Relationship of the encoded protein to mammalian clotting and growth factors. Mol. Cell. Biol. 6: 3094-3108.

Kidd, S., M.K. Baylies, G.P. Gasic, and M. Young. 1989. Structure and distribution of the Notch protein in developing Drosophila. Genes Dev. 3: 1113-1129.

Klambt, C., E. Knust, K. Tietze, and J.A. Campos-Ortega. 1989. 
Closely related transcripts encoded by the neurogenic gene complex Enhancer of split of Drosophila melanogaster. EMBO J. 8: 203-210.

Knust, E., K. Tietze, and J.A. Campos-Ortega. 1987. Molecular analysis of the neurogenic locus Enhancer of split of Drosophila melanogaster. EMBO . 6: 4113-4123.

Kopczynski, C.C. and M.A.T. Muskavitch. 1989. Complex spatio-temporal accumulation of alternative transcripts from the neurogenic gene Delta during Drosophila embryogenesis. Development 107: 623-636.

Kopczynski, C.C., A.K. Alton, K. Fectel, P.J. Kooh, and M.A.T. Muskavitch. 1988. Delta, a Drosophila neurogenic gene is transcriptionally complex and encodes a protein related to blood coagulation factors and epidermal growth factor of vertebrates. Genes Dev. 2: 1723-1735.

LaBonne, S.G., I. Sunitha, and A.P. Mahowald. 1989. Molecular genetics of pecanex, a maternal-effect neurogenic locus of Drosophila melanogaster that potentially encodes a large transmembrane protein. Dev. Biol. 136:1-16.

Laughon, A., S.B. Carroll, F.A. Storfer, P.D. Riley, and M.P. Scott. 1985. Common properties of proteins encoded by the Antennapedia complex genes of Drosophila melanogaster. Cold Spring Harbor Symp. Quant. Biol. 50: 253-262.

Lehmann, R., F. Jimenez, W. Dietrich, and J.A. Campos-Ortega. 1983. On the phenotype and development of mutants of early neurogenesis in $D$. melanogaster. Wilhelm Roux's Arch. Dev. Biol. 192: 62-74.

Markopoulou, K. and S. Artavanis-Tsakonas 1989. The expression of the neurogenic locus Notch during the postembryonic development of Drosophila melanogaster and its relationship to mitotic activity. J. Neurogenet. 6: 11-26.

Mitchison, T.J. and J. Sedat. 1983. Localization of antigenic determinants in whole Drosophila embryos. Dev. Biol. 99: $261-264$.

Mount, S.M. A catalogue of splice junction sequences. Nucleic Acids Res. 10: 459-471.

O'Hara, P.J., H. Horowitz, G. Eichinger, and E.T. Young. 1988. The yeast ADR6 gene encodes homopolymeric amino acid sequences and a potential metal-binding domain. Nucleic Acid Res. 16: 10153-10169.

Perrimon, N., D. Mohler, L. Engstrom, and A.P. Mahowald. 1986. X-linked female-sterile loci in Drosophila melanogaster. Genetics 113: 695-712.

Perry, L.J., F.J. Rixon, R.D. Everett, F.C. Frame, and D.J. McGeoch. 1986. Characterization of the $1 E 110$ gene of Herpes simplex virus type 1. J. Gen. Virol. 67: 2365-2380.

Pinkham, J.L., J.T. Oleson, and L.P. Guarente. 1987. Sequence and nuclear localization of the Saccharomyces cerevisiae HAP2 protein, a transcriptional activator. Mol. Cell. Biol. 7: $578-585$.

Pirrotta, V., E. Manet, E. Hardon, S.E. Bickel, and M .Benson. 1987. Structure and sequence of the Drosophila zeste gene. EMBO /. 6: 791-799.

Poole, S.J., L.M. Kauver, B. Drees, and T. Kornberg. 1985. The engrailed locus of Drosophila: Structural analysis of an embryonic transcript. Cell 40: 37-43.

Proudfoot, N. and Brownlee. 1976. 3' Non-coding region sequences in eucaryotic mRNA. Nature 263: 211-214.

Rao, Y., L.Y. Jan, and Y.N. Jan. 1990. Similarity of the product of the Drosophila neurogenic gene big brain to transmembrane channel proteins. Nature 345: 163-167.

Regulski, M., N. McGinnis, R. Chadwick, and W. McGinnis. 1987. Developmental and molecular analysis of Deformed, a homeotic gene controlling Drosophila head development. EMBO I. 6: 767-778.

Roth, S., D. Stein, and C. Nusslein-Volhard. 1989. A gradient of nuclear localization of the dorsal protein determines dorso- ventral pattern in the Drosophila embryo. Cell 59: 11891202.

Rushlow, C.A., K. Han, J.L. Manley, and M. Levine. 1989. The graded distribution of the dorsal morphogen is initiated by selective nuclear transport in Drosophila. Cell 59: 11651177.

Ruther, U. and B.M. Muller-Hill. 1983. Easy identification of cDNA clones. EMBO J. 2: 1791-1794.

Shellenbarger, D.L. and J.D. Mohler. 1978. Temperature-sensitive periods and autonomy of pleiotropic effects of 1/1) Ntsl, a conditional Notch lethal in Drosophila. Dev. Biol. 62: $432-446$.

Shepard, S.B., S.A. Broverman, and M.A.T. Muskavitch. 1989. A tripartite interaction among alleles of Notch, Delta and Enhancer of split during imaginal development of Drosophila melanogaster. Genetics 122: 429-438.

Simpson, P. 1990. Lateral inhibition and the development of the sensory bristles of the adult peripheral nervous system of Drosophila. Development (in press).

Smith, R.B. and K.S. Johnson. 1988. Single step purification of polypeptides expressed in Escherichia coli as fusions with glutathione S-transferase. Gene 67: 31-40.

Staden, R. 1986. The current status and portability of our sequence handling software. Nucleic Acids Res. 14: 217-231.

Steward, R. 1989. Relocalization of the dorsal protein from the cytoplasm to the nucleus correlates with its function. Cell 59: $1179-1188$.

Treier, M., C. Pfeifle, and D. Tautz. 1989. Comparison of the gap segmentation gene hunchback between Drosophila melanogaster and Drosophila virilis reveals novel modes of evolutionary change. EMBO I. 8: 1517-1525.

Vassin, H., J. Vielmetter, and J.A. Campos-Ortega. 1985. Genetic interactions in early neurogenesis of Drosophila me lanogaster. I. Neurogenet. 2: 291-308.

Vassin, H., K.A. Bremer, E. Knust, and J.A. Campos-Ortega. 1987. The neurogenic gene Delta of Drosophila melanogaster is expressed in neurogenic territories and encodes a putative transmembrane protein with EGF-like repeats. EMBO I. 6: $3431-3440$.

Weigel, D., E. Knust, and J.A. Campos-Ortega. 1987. Molecular organization of mastermind, a neurogenic gene of Drosophila melanogaster. Mol. Gen. Genet. 207: 374-384.

Wharton, K.A., K.M. Johansen, T. Xu, and S. Artavanis-Tsakonas. 1985a. Nucleotide sequence from the neurogenic locus Notch implies a gene product that shares homology with proteins containing EGF-like repeats. Cell 43: 567581.

Wharton, K.A., B. Yedvobnick, V.G. Finnerty, and S. Artavanis Tsakonas. 1985b. Opa: A novel family of transcribed repeats shared by the Notch locus and other developmentally regulated loci in D. melanogaster. Cell 40: 55-62.

Wilde, C.D. and M. Akam. 1987. Conserved sequence elements in the $5^{\prime}$ region of the Ultrabithorax transcription unit. $E M B O$ I. 6: 1393-1401.

Wright, T.R.F. 1970. The genetics of embryogenesis in Drosophila. Adv. Genet. 15: 261-395.

Xu, T., I. Rebay, R.J. Fleming, T.N. Scottgale, and S. ArtavanisTsakonas. 1990. The Notch locus and the genetic circuitry involved in early Drosophila neurogenesis. Genes Dev. 4: 464-475.

Yedvobnick, B., D. Smoller, P. Young, and D. Mills. 1988. Molecular analysis of the neurogenic locus mastermind of Drosophila melanogaster. Genetics 118: 483-497.

Yochem, J. and I. Greenwald. 1989. glp-1 and lin-12, genes implicated in distinct cell-cell interactions in C. elegans encode similar transmembrane proteins. Cell 58: 553-563. 


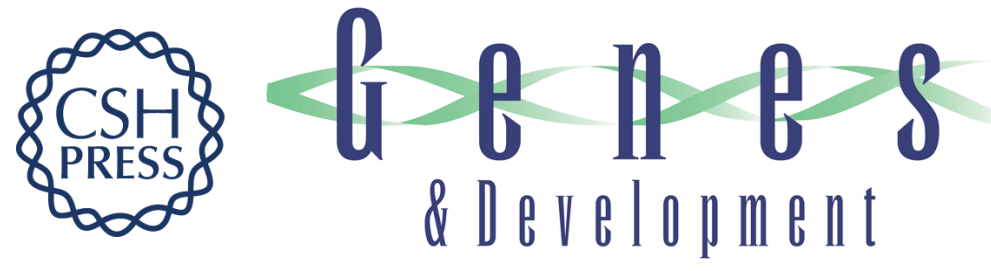

\section{The Drosophila neurogenic locus mastermind encodes a nuclear protein unusually rich in amino acid homopolymers.}

D Smoller, C Friedel, A Schmid, et al.

Genes Dev. 1990, 4:

Access the most recent version at doi:10.1101/gad.4.10.1688

References This article cites 72 articles, 14 of which can be accessed free at:

http://genesdev.cshlp.org/content/4/10/1688.full.html\#ref-list-1

License

Email Alerting

Service

Receive free email alerts when new articles cite this article - sign up in the box at the top right corner of the article or click here.

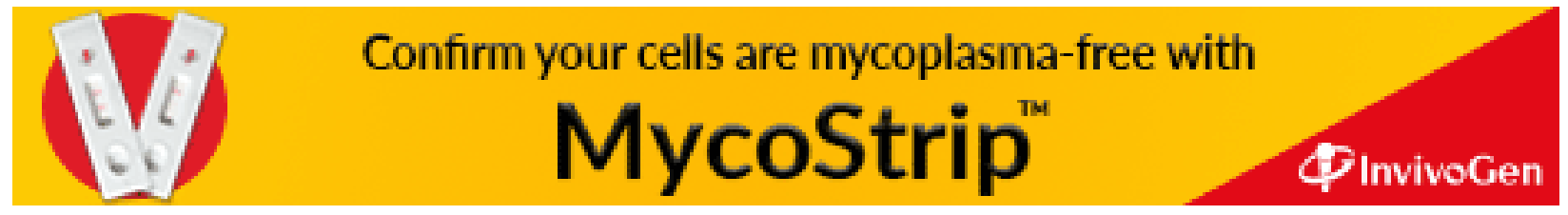

